\title{
Tailoring Plasticity of Austenitic Stainless Steels for Nuclear Applications: Review of Mechanisms Controlling Plasticity of Austenitic Steels at Temperature Below $400^{\circ} \mathrm{C}$
}

\author{
G. Meric de Bellefon ${ }^{1 *}$ - J. C. van Duysen ${ }^{2,3,4}$ \\ University of Wisconsin-Madison \\ EDF R\&D \\ University of Tennessee-Knoxville \\ Unité Matériaux et Transformation (UMET) CNRS, Université de Lille \\ Email: mericdebelle@wisc.edu, postal address: Engineering Physics, University of Wisconsin- \\ Madison, 1500 Engineering Drive, Madison, WI 53706
}

\begin{abstract}
AISI 304 and 316 austenitic stainless steels were invented in the early 1900s and are still trusted by materials and mechanical engineers in numerous sectors because of their good combination of strength, ductility, and corrosion resistance, and thanks to decades of experience and data. This article is part of an effort focusing on tailoring the plasticity of both types of steels to nuclear applications. It provides a synthetic and comprehensive review of the plasticity mechanisms in austenitic steels during tensile tests below $400^{\circ} \mathrm{C}$. In particular, formation of twins, extended stacking faults, and martensite, as well as irradiation effects and grain rotation are discussed in details.
\end{abstract}

\section{Introduction}

AISI 304 and 316 austenitic stainless steels and their lower carbon content versions 304L and $316 \mathrm{~L}$ are extensively used in Light Water Reactors. They can be in annealed or cold-worked (in the bulk due to drawing or in the surface layer due to machining) conditions. Their in-service temperature is lower than about $370^{\circ} \mathrm{C}$, and in some areas they are highly neutron irradiated (up to about 4 $\mathrm{dpa} /$ year). In service, they may exhibit some degradation, which entails high maintenance costs. For instance, cases of stress corrosion cracking (SCC), irradiation-assisted stress corrosion cracking (IASCC) and irradiation-induced loss of ductility have been reported [1,2,3,4].

304 and 316 steels were put forward in the early 1900s, and were among the firsts of a series of austenitic steels named the AISI 300 series, which have $\mathrm{Cr}$ (15 to $26 \mathrm{wt} \%)$ and $\mathrm{Ni}$ ( 8 to $22 \mathrm{wt} \%$ ) as the major alloying elements. Both grades have been adopted for a multitude of applications because of their good corrosion resistance, relatively high strength and ductility, low tendency to brittle failure even at cryogenic temperatures, and relative low cost. Today material and mechanical engineers in numerous sectors still extensively rely on 304(L) and 316(L) steels because of decades of experience and data.

While maintaining this high confidence level, it should be possible to provide new benefits to 304(L) and 316(L) steel users by tailoring steel plasticity according to applications. For instance, one could attempt to increase their fracture toughness or SCC resistance by promoting twinning- or slipbased plasticity at crack tip. One could also attempt to reduce (IA)SCC initiation rate by adapting twin or martensite volume fraction in surface layers. Another example could be to adjust their thermomechanical behavior to the stress, strain rate, and temperature paths imposed by accidental conditions. Such plasticity tailoring can be obtained from adjustments to chemical composition, grain size, texture, cold-working treatment, and machining conditions, while staying within the AISI specification ranges. There have already been some tailoring efforts on austenitic stainless steels. For instance, composition ranges of 316 have been slightly modified to enhance properties such as resistance to intergranular stress corrosion cracking (leading to $316 \mathrm{~L}$ by restricting $\mathrm{C}$ ), high temperature resistance ( $316 \mathrm{H}$ by increasing $\mathrm{C})$, low activation ( $316 \mathrm{~L}-\mathrm{NG}$, by strongly restricting $\mathrm{Co}$ ), high strength (leading to $316 \mathrm{~N}$ and $316 \mathrm{LN}$ by increasing $\mathrm{N}$ ), or overall performance for the International Thermonuclear Experiment Reactor - ITER - (316LN-IG, by severely tightening chemical specification ranges). Similarly, for other types of austenitic alloys (Alloy $800 \mathrm{H}$, and Inconel 617), it was shown that grain boundary engineering treatments could significantly improve corrosion resistance and strength [5]. A comprehensive review of recent developments in stainless steels is available in [6]. 
Tailoring 304(L) and 316(L) steel plasticity can leverage the tremendous work done during the past 90 years in understanding fcc materials deformation. However, because of the sensitivity of the deformation mechanisms and microstructures to experimental conditions, and the high number of influencing parameters, the current corpus of results and models is very large, diverse, and partially inconsistent. Consequently, no comprehensive and consistent picture of plasticity of austenitic steels has been drawn so far.

The present review is part of an effort aimed at assessing the possibility of tailoring plasticity of 304L and 316L steels for Light Water Reactor applications. It proposes a synthesis of the mechanisms that control the plasticity of austenitic steels during tensile tests at temperature below $400^{\circ} \mathrm{C}$. The drawn understanding partly relies on data and information obtained on pure metals or non-steel fcc alloys whenever relevant. Section 2 and 3 describe the intragranular mechanisms in unirradiated and irradiated states, respectively, and Section 4 gives an overview of the mechanisms that control grain rotation in polycrystals.

\section{Intragranular Plasticity Mechanisms}

During tensile tests in the $200-400{ }^{\circ} \mathrm{C}$ range (these temperature thresholds may vary significantly depending on the steel), plasticity of annealed austenitic steel is mainly controlled by i) slip, and ii) dynamic strain aging (e.g., [7,8]). Below about $200^{\circ} \mathrm{C}$, at least three additional intragranular plasticity mechanisms may occur: iii) formation of extended stacking faults (e.g., [9,10]), iv) twinning (e.g., $[9,11,12,13])$, and v) martensite formation (e.g., [7,9]). These last three mechanisms are similar microstructural processes in that they all lead to constrained plate-shaped regions in the parent crystal. They are currently taken advantage of by the automotive and cryogenic sectors to develop steels with enhanced properties, such as TWIP (Twinning Induced Plasticity) (e.g., [14,15]), and TRIP (TRansformation Induced Plasticity) (e.g., [15,16]).

These five mechanisms are competing and interacting with one another to produce plastic deformation within grains. Their occurrence and characteristics are controlled by a variety of material, experimental, and mechanical variables, as depicted in Fig. 1: chemical composition, grain size, texture, temperature, strain, strain rate, and stress. It should be noticed that for some applications, magnetic field has also to be taken into account (e.g., [17]). All these variables affect the plastic behavior by their impact on austenite stability and dislocation mobility.

After discussing the dissociation of perfect dislocations in fcc crystals in the first Paragraph, the subsequent five Paragraphs are respectively dedicated to the five aforementioned plasticity mechanisms. A last Paragraph reviews how temperature, chemical composition, and strain rate control the transition between some of those mechanisms.

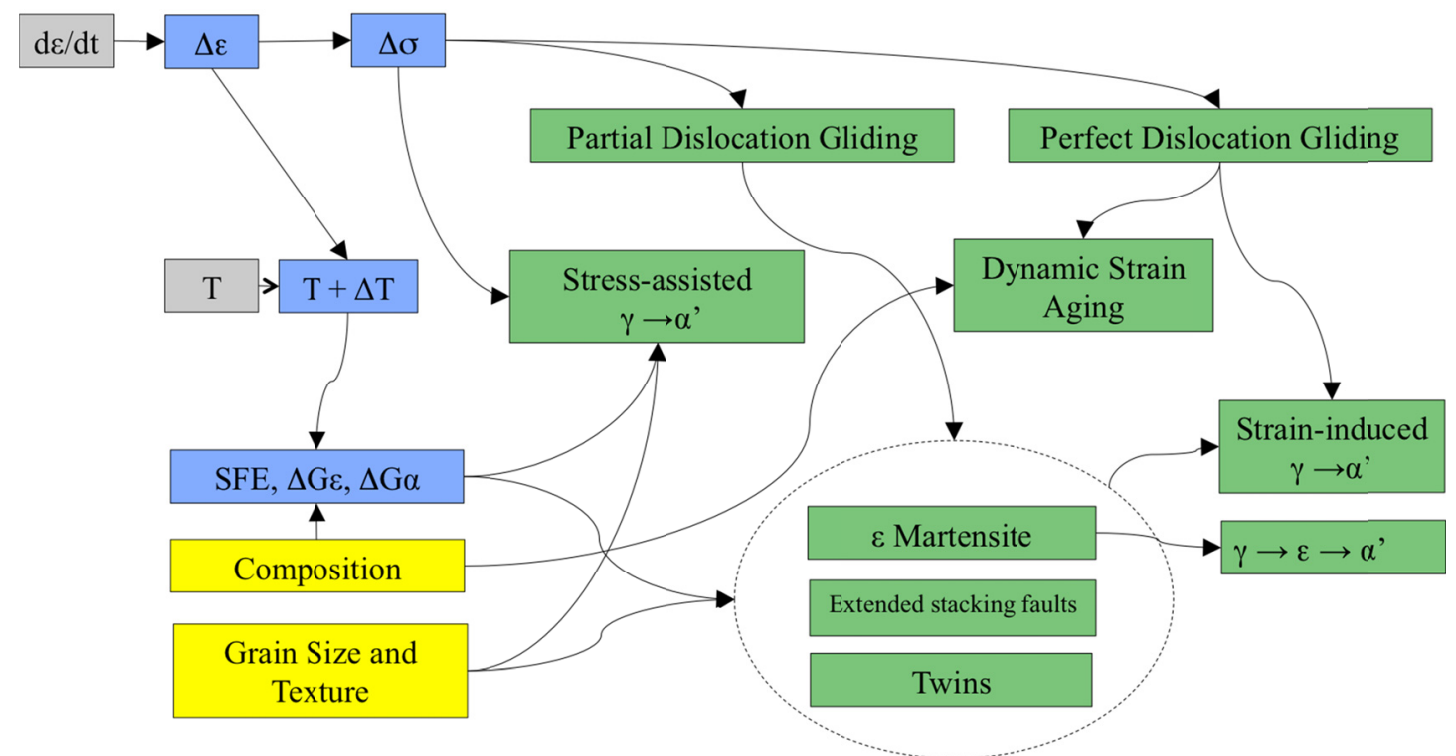

Fig. 1. Main experimental (grey) and material (yellow) variables that impact the physical and 
thermodynamic parameters (blue), and the mechanisms (green) controlling the plasticity of austenitic steels during tensile tests with imposed strain rate, below $400^{\circ} \mathrm{C}-\mathrm{d} \varepsilon / \mathrm{dt}$ : imposed strain rate, $\mathrm{T}$ : test temperature, $\Delta \mathrm{T}$ : increase of material temperature due to adiabatic heating, SFE: Stacking Fault Energy, $\Delta \varepsilon$ : strain increase, $\Delta \sigma$ : stress increase to meet imposed strain, $\Delta \mathrm{G}_{\varepsilon}$ : free energy difference linked to formation of $\varepsilon$-martensite, $\Delta \mathrm{G}_{\alpha}$ : free energy difference linked to formation of $\alpha$ '-martensite.

\subsection{Dissociation of Perfect Dislocations}

In fcc crystals, perfect dislocations belong to one of the twelve $\{111\} a / 2<110>$ slip systems (where $a$ is the lattice parameter). In order to reduce their strain energy, perfect dislocations may dissociate into two $a / 6<112>$ Shockley partials on the same slip plane (see Fig. 2), according to Eq. (1), for instance. This phenomenon strongly impacts slip-based plasticity, and is at the origin of twinning and martensite formation processes in fec crystals.

$$
\frac{a}{2}[011]_{(1 \overline{1} 1)}=\frac{a}{6}[121]_{(1 \overline{1} 1)}+\frac{a}{6}[\overline{1} 12]_{(1 \overline{1} 1)}
$$

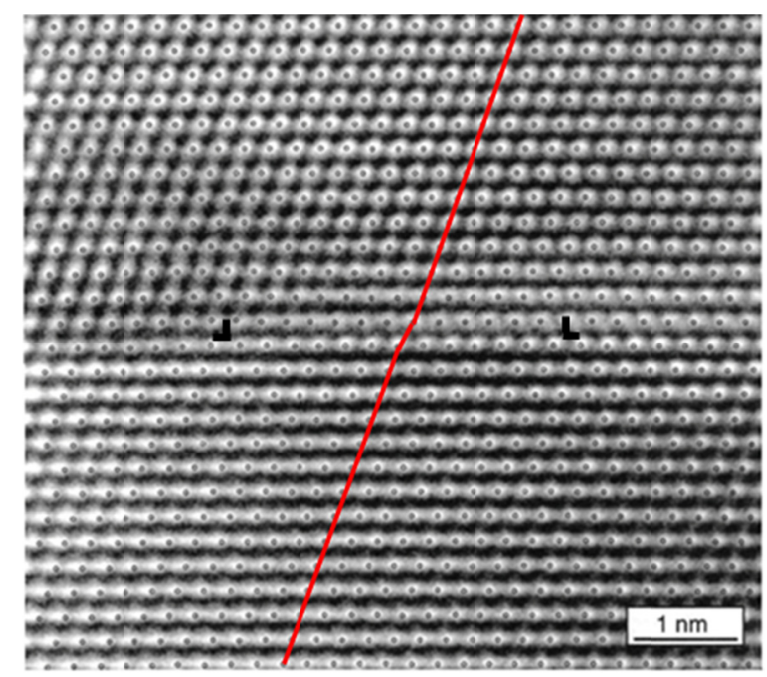

Fig. 2. High-Resolution Transmission Electron Microscopy (TEM) image of a dissociated dislocation in $\mathrm{Au}$. The positions of the Shockley partials are indicated by black symbols. The deviation of the line reveals the stacking fault, from [18].

The elastic interaction between the two Shockley partials leads to a repulsive force between them. In the approximation where Poisson's ratio is null, the repulsion force per unit length of dislocation line does not depend on their character and can be given by [19]:

$F=\frac{G b^{2}}{4 \pi d}$

with: $d=$ distance between partials, $b=$ modulus of the Burgers vector of the Shockley partials, $G=$ shear modulus). Since $a / 6<112>$ Burgers vectors are not fcc lattice vectors, the Shockley partial that glides ahead (named leading partial) leaves behind it a stacking fault (fault in the stacking of $\{111\}$ planes), see Fig. 2. The passing of the second partial (named trailing partial) removes the stacking fault and restores the fcc $\{111\}$ stacking order. Formation of a stacking fault is energetically unfavorable and is equivalent to an attraction force per unit length of dislocation line between the two Shockley partials equals to $\gamma$, the stacking fault energy (SFE). At an equilibrium distance $w$, repulsion and attraction forces are balanced. In absence of external stress and for a null Poisson's ratio, this distance can be assessed with Eq. (3), which shows that the higher the SFE is, the lower the equilibrium distance is. It can be stated that more precise approaches to assess $w$ have been derived. For instance, equations taking into account orientation of partials, applied stress [20], and friction forces [21] on partials have recently been proposed (see Paragraph 2.3). 
$w=\frac{G b^{2}}{4 \pi \gamma}$

The SFE plays a key role in dislocation gliding and other deformation modes of metallic materials. In the past 60 years, large efforts have been devoted to its measurement in fcc pure metals and alloys either by Transmission Electron Microscopy (TEM) (e.g., [22]), X Ray diffraction (XRD) (e.g., [23]) and neutron diffraction (e.g., [24]). The XRD (e.g., [25,26]) and neutron diffraction methods rely on correlations between stacking fault probability (ratio of the area of faulted $\{111\}$ plan to the total $\{111\}$ plan area in the considered volume), dislocation density, and SFE. Recent XRD techniques use in-situ bending to vary the separation between partials [27]. TEM relies on measurement of dissociation distance at triple node junctions (e.g., [28]) or along straight dislocation lines (e.g., [29]). It is generally suitable for measurement of SFE lower than $50 \mathrm{~mJ} / \mathrm{m}^{2}$ because of large separation between partials, while XRD is used above $50 \mathrm{~mJ} / \mathrm{m}^{2}[30]$.

Expressions derived from multivariate linear regression of experimental data have been put forward to estimate $\operatorname{SFE}(\gamma)$ from alloy chemical compositions. In Fig. 3 and Fig. 4, some expressions determined for Fe-Cr-Ni-based alloys at room temperature are compared with experimental measures for several 304 and 316 steels. The used formulas are (alloying element in $\mathrm{wt} \%)$ :

- Schramm et al. [30]: $\gamma\left(\mathrm{mJ} / \mathrm{m}^{2}\right)=-53+6.2 \mathrm{Ni}+0.7 \mathrm{Cr}+3.2 \mathrm{Mn}+9.3 \mathrm{Mo}$,

- Rhodes et al. [31]: $\gamma\left(\mathrm{mJ} / \mathrm{m}^{2}\right)=1.2+1.4 \mathrm{Ni}+0.6 \mathrm{Cr}+17.7 \mathrm{Mn}-44.7 \mathrm{Si}$,

- Pickering [32]: $\gamma\left(\mathrm{mJ} / \mathrm{m}^{2}\right)=25.7+2 \mathrm{Ni}+410 \mathrm{C}-0.9 \mathrm{Cr}-77 \mathrm{~N}-13 \mathrm{Si}-1.2 \mathrm{Mn}$,

- Brofman et al. [33]: $\gamma\left(\mathrm{mJ} / \mathrm{m}^{2}\right)=16.7+2.1 \mathrm{Ni}-0.9 \mathrm{Cr}+26 \mathrm{C}$,

- Qi-Xun et al. [34]: $\gamma\left(\mathrm{mJ} / \mathrm{m}^{2}\right)=39+1.59 \mathrm{Ni}-1.34 \mathrm{Mn}+0.06 \mathrm{Mn}^{2}-1.75 \mathrm{Cr}+0.01 \mathrm{Cr}^{2}+15.21$ Mo - 5.59 Si $-60.69(\mathrm{C}+1.2 \mathrm{~N})^{0.5}+26.27(\mathrm{C}+1.2 \mathrm{~N})(\mathrm{Cr}+\mathrm{Mn}+\mathrm{Mo})^{0.5}+0.61[\mathrm{Ni}(\mathrm{Cr}+$ $\mathrm{Mn})]^{0.5}$

- Ojima et al. [35]: $\gamma\left(\mathrm{mJ} / \mathrm{m}^{2}\right)=5.53+1.40 \mathrm{Ni}-0.16 \mathrm{Cr}+17.10 \mathrm{~N}$,

- Yonezawa et al. [29]: $\gamma\left(\mathrm{mJ} / \mathrm{m}^{2}\right)=-7.1+2.8 \mathrm{Ni}+0.49 \mathrm{Cr}+2.0 \mathrm{Mo}-2.0 \mathrm{Si}+0.75 \mathrm{Mn}-5.7 \mathrm{C}$ $-24 \mathrm{~N}$,

- Meric de Bellefon et al. [36]: $\gamma\left(\mathrm{mJ} / \mathrm{m}^{2}\right)=6.7+1.5 \mathrm{Ni}+8.1 \mathrm{Ni} \mathrm{C}-420 \mathrm{C} \mathrm{Si}-16 \mathrm{Mo} \mathrm{N}+290$ $\mathrm{Mo} \mathrm{C}+0.5 \mathrm{Ni} \mathrm{Si}$.

Experimental values of SFE for 304 steels range from $8 \mathrm{~mJ} / \mathrm{m}^{2}$ [37] to $40 \mathrm{~mJ} / \mathrm{m}^{2}$ [38], and for 316 steels range from $14.2 \mathrm{~mJ} / \mathrm{m}^{2}$ [35] to $78 \pm 6 \mathrm{~mJ} / \mathrm{m}^{2}$ [30]. As illustrated in Fig. 3 and

Fig. 4, discrepancies between calculated values, as well as between these values and experimental ones are often large. Approaches based on advanced regression methods are under development to put forward better formulas [36]. 


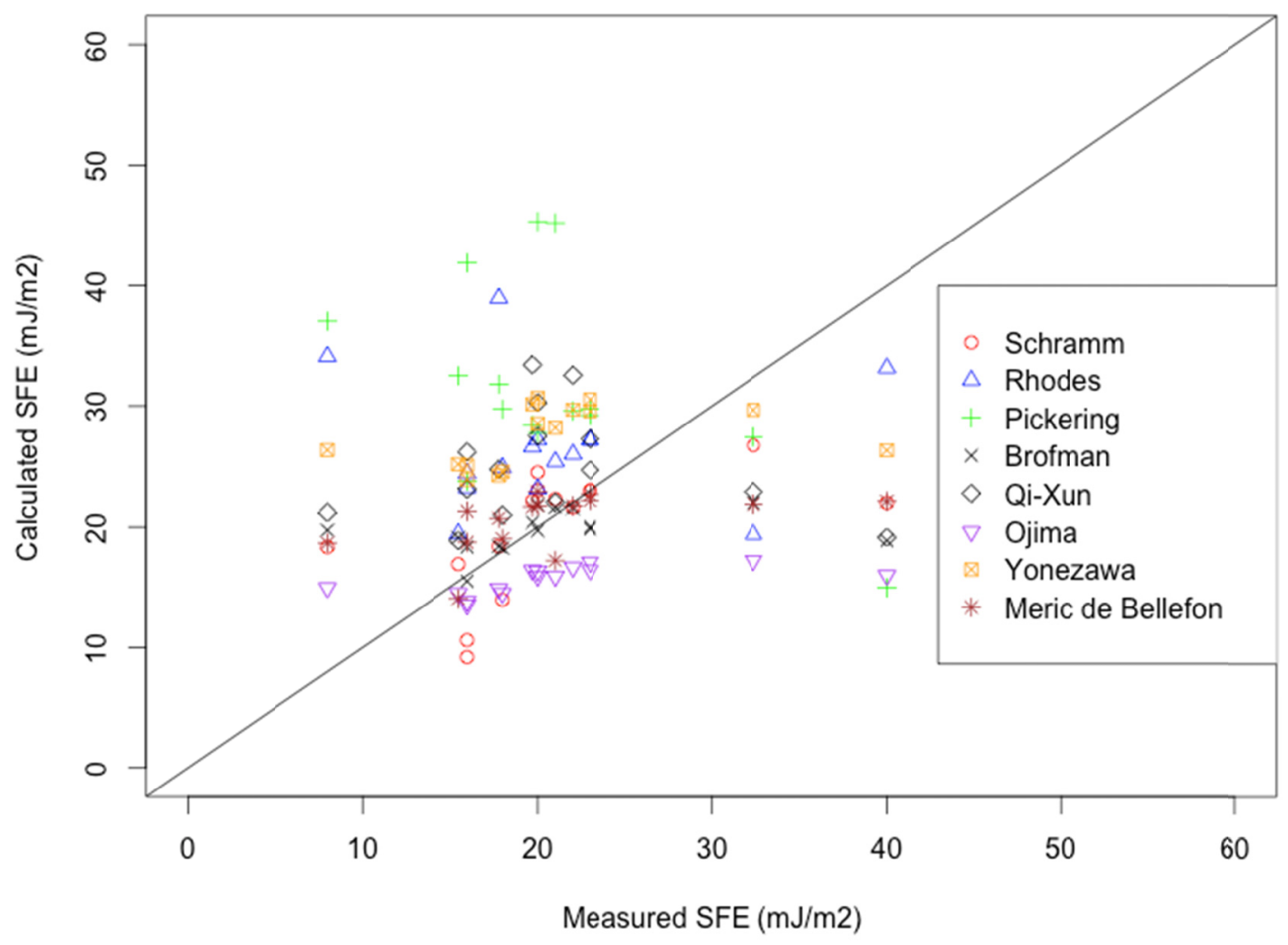

Fig. 3. Calculated SFE vs. measured SFE for 304 steels. Experimental values of SFE are from $[30,35,29,37,38,39,40,41,42,43,44,45]$. 


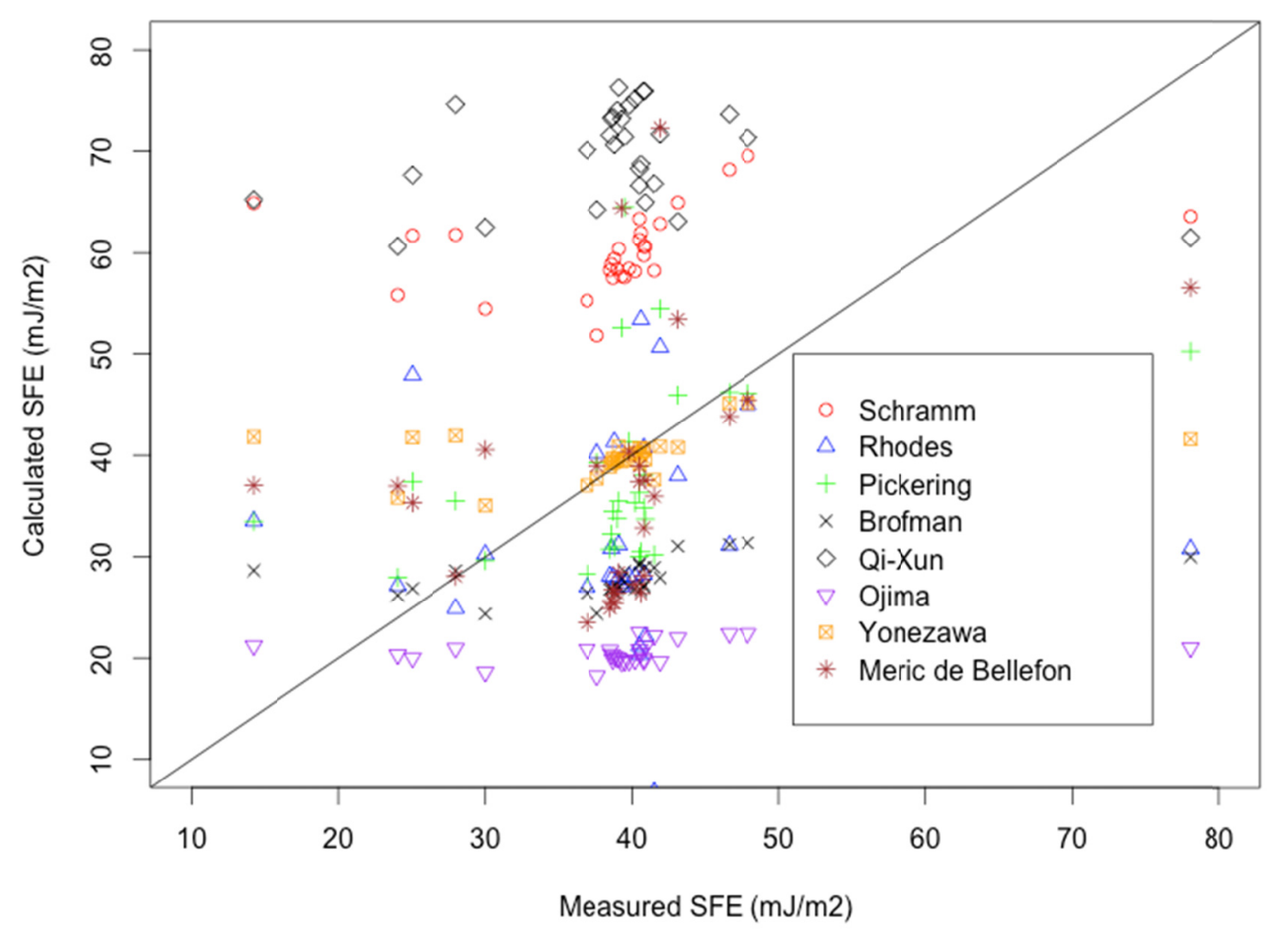

Fig. 4. Calculated SFE vs. measured SFE for 316 steels. Experimental values of SFE are from $[29,30,35,46,47,48,49]$.

The aforementioned discrepancies can be explained by at least the four following reasons:

- Experimental approaches to measure the SFE may lead to significant uncertainty, in particular because of many possible sources of bias (e.g., partial dislocation pinning by carbon atoms [50]).

- TEM measurement of the SFE relies on the separation distance between partials (Eq. (3)). However, first principle simulations (e.g., $[51,52,53,54])$ indicate that the width between two partials does not only depend on the SFE, but also on the fault energy evolution along with the shearing amplitude from non-faulted to faulted fcc stacking, as shown in Fig. 5. The function expressing this evolution (Fig. 5-b) is named the Generalized Stacking Fault Energy (GSFE) [55], and is represented by a curve along the $<112>$ direction, or a surface if other shearing directions are accounted for. Several energy peaks can be pointed out along the curve: $\gamma_{\mathrm{us}}$ is termed the unstable stacking fault energy [56] and $\gamma_{\mathrm{m}}$ the maximum energy; in this representation, the usual SFE is termed the stable or intrinsic stacking fault

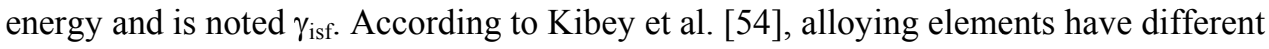
effects on each energy peaks, and the width between the two partials is controlled by the whole GSFE, and particularly by $\gamma_{\text {us }}$, and not only by $\gamma_{\text {isf. Nevertheless, analysis based }}$ only on $\gamma_{\text {isf }}$ (i.e., SFE) are still largely spread and have brought a lot in understanding and modeling the plastic behavior of fcc materials.

- Due to friction forces, the stacking fault width depends on the partials history. If equilibrium is reached by the two partials getting closer, the width will be larger than if the equilibrium is reached by the two partials parting away, as shown in [21]. 
- A "universal" equation relating SFE and chemical composition might not be established.

Indeed, first principle calculations (e.g., [57]) predict that one alloying element might have opposite effects on the SFE depending on the composition of the other elements. Some elements are also reported to have non-monotonic effect on SFE, as observed experimentally [58] and though first-principle simulations for nitrogen added to 316 steel [54], and calculated through a thermochemical model for silicon in FeMnC steels [59].

There were attempts to assess stacking fault energies from thermodynamic calculations (e.g., $[59,60,61])$. In particular, Olson and Cohen [61] proposed that the SFE in fcc materials be modeled as the energy stored in an $\varepsilon$-martensite platelet with a thickness of two $\{111\}$ planes. Then, by neglecting the elastic energy of the two partials bounding the fault, they established Eq. (4), where $\Delta G_{c}$ is the chemical free energy difference between the austenite and $\varepsilon$ martensite phases, $\Delta G_{s}$ is the strain energy related to austenite $\rightarrow \varepsilon$ martensite transformation, $\lambda$ is the interfacial energy of the coherent austenite/ $\varepsilon$ interface, and $\mathrm{n}$ is the fault thickness (equal to 2 for an intrinsic stacking fault).

$\gamma=n \rho\left(\Delta G_{c}+\Delta G_{s}\right)+2 \lambda$

A literature review of values for $2 \lambda$ is available in [62] - it has been estimated between 10 to 20 $\mathrm{mJ} / \mathrm{m}^{2}$ in Fe-Cr-Ni alloys, and from 10 to $54 \mathrm{~mJ} / \mathrm{m}^{2}$ in Fe-Mn steels. Its magnitude seems to be relatively independent of temperature and composition [40]. For an intrinsic fault in Fe-Mn steels, $2 \rho \Delta G_{s}$ was determined to be $1-4 \mathrm{~mJ} / \mathrm{m}^{2}$ [63]. As shown in Paragraphs 2.5 and 2.6, Eq. (4) has many implications.

In the past 10 years, first principle simulations on model alloys (up to quaternary alloys) revealed the main atomic-level mechanisms responsible for the variation of the SFE with alloying and temperature. For instance, in Fe-Cr-Ni-based alloys, electronic, volume, and magnetic contributions of alloying atoms to SFE have been quantified (e.g., $[57,64,65])$.

a)

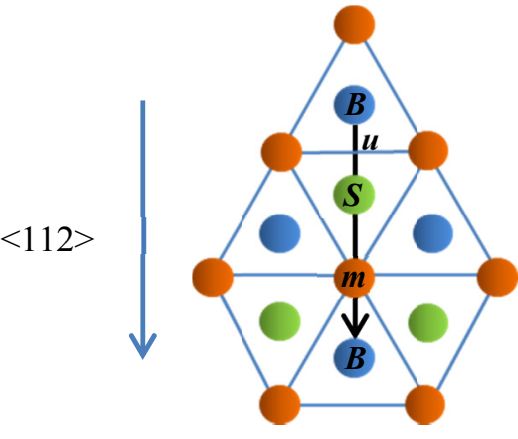

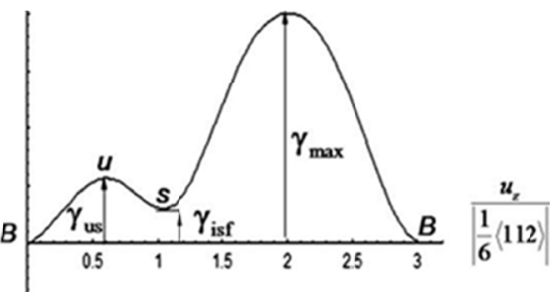

b)

Fig. 5. a) Shear configurations along a $<112>$ direction, b) Fault energy evolution with the shearing amplitude, from [54].

The temperature dependence of the SFE was studied by Remy and Pineau [22], who published a survey of experimental data for several fcc metals and alloys, including $\mathrm{Fe}-\mathrm{Cr}$-Ni alloys for which the dependence is $5-710^{-2} \mathrm{~mJ} / \mathrm{m}^{2} . \mathrm{C}^{-1}$ in the range $-123^{\circ} \mathrm{C}$ to $127^{\circ} \mathrm{C}$. In some alloys (e.g., austenitic Fe-Mn steels), the temperature dependence of the SFE can be strongly affected by the anti-ferro/paramagnetic transitions of the austenite and $\varepsilon$-martensite phases. Below their respective Néel temperature (TN), magnetic contributions to the free energy of the austenite $\rightarrow \varepsilon$-martensite transformation have to be added for the calculation of the SFE in Eq. (4). In Fe- $22 \% \mathrm{Mn}-0.6 \% \mathrm{C}$, for which $\mathrm{TN}_{\text {austenite }}$ is around room temperature and $\mathrm{TN}_{\varepsilon \text {-martensite }}$ is around $-150^{\circ} \mathrm{C}$, it was observed [11] that with decreasing temperature below room temperature, the decrease of the chemical contribution to the free energy is counterbalanced by an increase of the magnetic contribution. Thus, the temperature dependence of the SFE is weak below room temperature. In the 300 stainless steel series, $\mathrm{TN}_{\text {austenite }}$ was predicted [66] to be lower than $-215^{\circ} \mathrm{C}$. Thus, the magnetic contribution has to be considered only for cryogenic applications. 
Perfect screw dislocation segments may cross-slip, i.e., move from one slip plane to another one (the cross-slip plane), for instance when encountering an obstacle. Ability to cross-slip reduces work hardening by limiting dislocation pile-ups and favoring annihilation of dislocations having opposite Burgers vectors. The continuum theory of dislocation predicts that dissociated dislocations must be locally totally constricted, either by the applied stress or thermal fluctuations, to cross-slip at the constriction [67]. This happens more easily for high-SFE metals. Atomic simulations suggest that the constriction might be considered as total as soon as the distance between the two partials is below a lower limit, which is about $1.55 b_{p}$ for copper, where $b_{p}$ is the modulus of the Burgers vector of the perfect dislocation [68]. Below this limit, the energy of the dissociated dislocation can be considered equal to the energy of the perfect dislocation. The same atomic simulations also suggested that cross-

slip can happen even with non-complete constriction if the stress is high enough. As explained in Paragraph 2.7, competition between cross-slip and twinning has a large impact on the plasticity of fcc materials, in particular austenitic steels.

\subsection{Gliding of Perfect Dislocations}

The component of the applied stress $(\sigma)$ which controls dislocation glide is termed the resolved shear stress $(\tau)$ and is given by $\tau=\sigma \cos \phi \cos \lambda$, where $\phi$ et $\lambda$ are the angles between the tensile axis and the normal of the slip plane, and between the tensile axis and the Burgers vector of the dislocation, respectively; $\cos \phi \cos \lambda$ is termed the Schmid factor. According to Schmid law [69], a slip system is activated when its resolved shear stress reaches a critical value (CRSS). The CRSS can correspond to either dislocation nucleation or glide. It is often considered that this stress is the same for all slip systems. However, in single fcc crystals where the nucleation of dislocation is the limiting factor, atomistic simulations $[70,71]$ predicted that the CRSS might be strongly orientation-dependent, as illustrated in Fig. 6 for copper. It can be noticed that dislocation-based plasticity requires a much higher CRSS for $<111>$ grains (i.e., grains with $<111>$ direction close to the tensile axis) than for $<100>$ or $<110>$ grains.

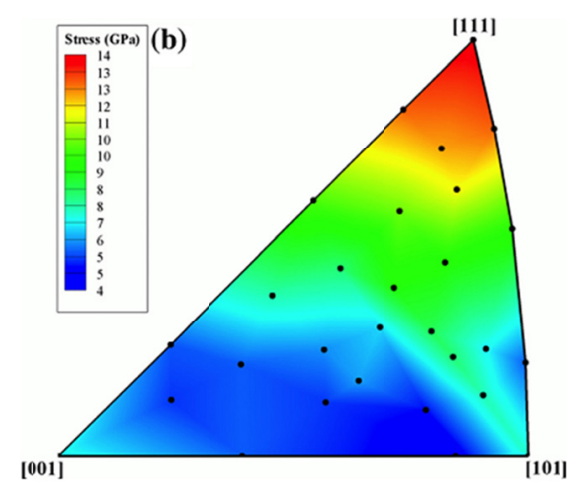

Fig. 6. Contour plot of the CRSS in pure $\mathrm{Cu}$ as a function of crystal orientation with respect to tensile axis. Simulations were run at $-263^{\circ} \mathrm{C}$ in presence of a stacking fault tetrahedral from which dislocations are nucleated, from [71].

Interactions among dislocations of active slip systems lead the material to work harden. In the assumption that the CRSS is not orientation-dependent, slip systems most easily activated are expected to be the ones with the highest Schmid factors. Table 1 gives the highest Schmid factors for $<110>$ $\{111\}$ slip systems in fcc crystals, and the number of slip systems with an identical Schmid factor considering four grain orientations. In single crystals, for low-symmetry orientations such as $<123>$, experiments generally agree with Schmid law, and show an easy-slip region with only one activated slip system at the onset of deformation (e.g., in 316 stainless steel single crystal [58]). For highsymmetry orientations such as $\langle 100\rangle,<111>$ and $<110>$, Table 1 indicates that several slip systems should be activated, leading to high work hardening at the onset of deformation. However experiments 
deviate from these conclusions. In $<111>$ and $<100>$ single crystals of various fcc metals and alloys, it was observed that only half of the expected number of slip systems or less is activated

$[72,73,74,75,76]$. Several mechanisms were put forward to explain this behavior, for instance in $[73,75,77]$. In [77], the proposed mechanism involves the strong interactions between dislocations with collinear Burgers vectors, which prevent the simultaneous operations of a slip system and its cross-slip system. The behavior of $<101>$ crystals was reported to be similar to that of a low-symmetry orientation with only one system activated. This is attributed to slight misorientation off the $<101>$ axis, causing the crystal to rotate rapidly away from $<101>$ into low-symmetry directions (whereas $<111>$ and $<100>$ are more stable with respect to orientation fluctuation) [78].

Table 1. Schmid factors for perfect dislocations and partial dislocations in fcc crystals. Only cases where the Schmid factor is higher on the leading than on the trailing partial are considered.

\begin{tabular}{|l|l|l|}
\hline Grain orientation & $\begin{array}{l}\text { Maximum Schmid factor for perfect } \\
\text { dislocations (\# of systems) }\end{array}$ & $\begin{array}{l}\text { Leading partial / Trailing partial Schmid } \\
\text { factor (\# of systems) }\end{array}$ \\
\hline$<111>$ & $0.27(6)$ & $0.31 / 0.16(6)$ \\
\hline$<110>$ & $0.41(4)$ & $0.47 / 0.24(4)$ \\
\hline$<100>$ & $0.41(8)$ & $0.24 /-0.24(8)$ \\
\hline$<123>$ & & $0.30 / 0.00(1)$ \\
& & $0.47 / 0.13(1)$ \\
& $0.47(1)$ & $0.47 / 0.34(1)$ \\
& & $0.27 / 0.24(1)$ \\
\hline
\end{tabular}

At low strain, dislocations tend to concentrate in bands, named slip bands, which are parallel to $<111>$ planes in fcc crystals. On polished surfaces, closely-spaced slip steps materialize each band. Band prevalence was observed to be promoted by increasing strain rate and stress, and to depend on grain orientation. Their origin is still unclear and many models have been proposed to explain their formation. Most models (e.g., [79,80,81]) involve double cross-slip events: a screw dislocation transitions out of its primary slip plane onto its cross-slip plane, and then cross-slips back onto another primary plane parallel to its original one. In doing so, the dislocation glides in two parallel, nearby planes and may be transformed into a new Franck-Read source in the second plane. This phenomenon can gradually build up a slip band from very few initial dislocations. In principle, it requires a SFE high enough to allow cross-slip, but not too high to prevent dislocations from leaving the bands and form a cell-based structure as soon as the stress rises. Dislocation dynamics simulations [79] showed that slip bands preferentially form in grains loaded in the $<111>$ direction rather than $<100\rangle$, and that they are the fastest possible mechanism by which plastic flow can proceed since dislocation generation rates and mobility are highest within slip bands. However, they showed no direct relationship between slip band formation and work hardening.

In some high-SFE steels, for instance FeMnAl, slip bands are observed during tensile test until rupture, and provide high strength and elongation. This phenomenon is named Micro Band-Induced Plasticity, and is described for instance in [15,82]. A proposed mechanism is that dislocations remain in slip bands even at high stresses due to short-range order. Such order corresponds to the appearance of solid solution configurations in which the distribution of certain types of atoms is no longer fully uniform, for instance by creation of C-Mn or N-Cr pairs, which increases the friction stress. The first dislocation destructs the order by gliding (e.g., [83]), and is easily followed by other dislocations.

At large strains in single crystals, the strain hardening behavior is still strongly dependent on the orientation, as reviewed and modeled in [84] and observed in Fig. 7. In general, $<111>$ grains exhibit the stronger strain hardening. To the authors' knowledge, no detailed experimental study of the dependence of perfect dislocation behavior on grain orientation has been done for polycrystalline austenitic steels at high strain. However, such studies have been conducted for pure polycrystalline copper, aluminum, and nickel (i.e., with higher SFE than 304 and 316 steels) through tensile tests at room temperature (e.g., [85,86]). They revealed (see brief synthesis in [87]) strong differences of dislocation patterns according to grain orientation with respect to the tensile axis, as shown in Fig. 8 . Furthermore, extensive TEM, Scanning Electron Microscopy (SEM) and Electron Backscattering Diffraction (EBSD) studies (e.g., $[12,87,88]$ ) revealed that as strain increases, plastic strain becomes 
heterogeneous within grains and among grains (see Fig. 9). Local crystallographic disorientation between dislocation cells or between grain center and grain boundaries may reach up to $15^{\circ}[12,87]$.

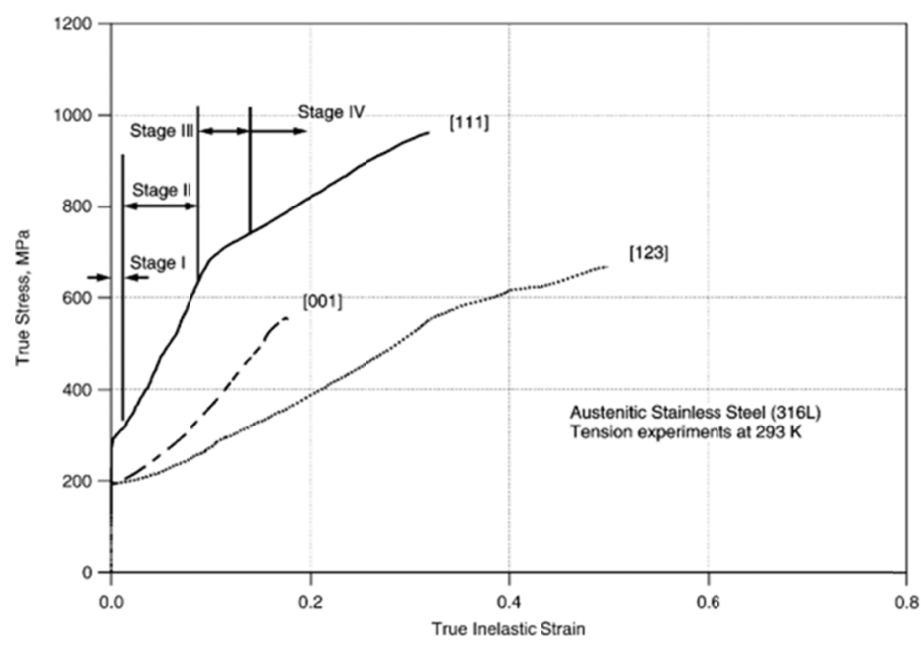

Fig. 7. True stress/true strain curve of 316L stainless steel single crystals having different orientations with respect to the tensile axis, tensile tested at $20^{\circ} \mathrm{C}$ [58].

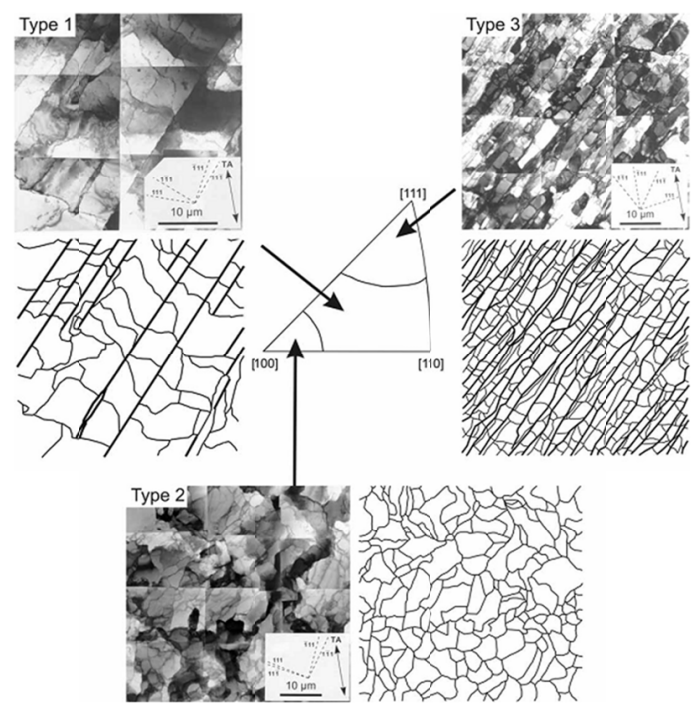

Fig. 8. Dislocation structures in polycrystalline pure aluminum (99.99\%) deformed at room temperature. In the strain range from 0.05 to 0.34 , at least three dislocation wall organizations can be observed depending on the orientation with respect to the tensile axis. The micrographs shown in this figure were taken at a tensile strain of 0.14 [86].
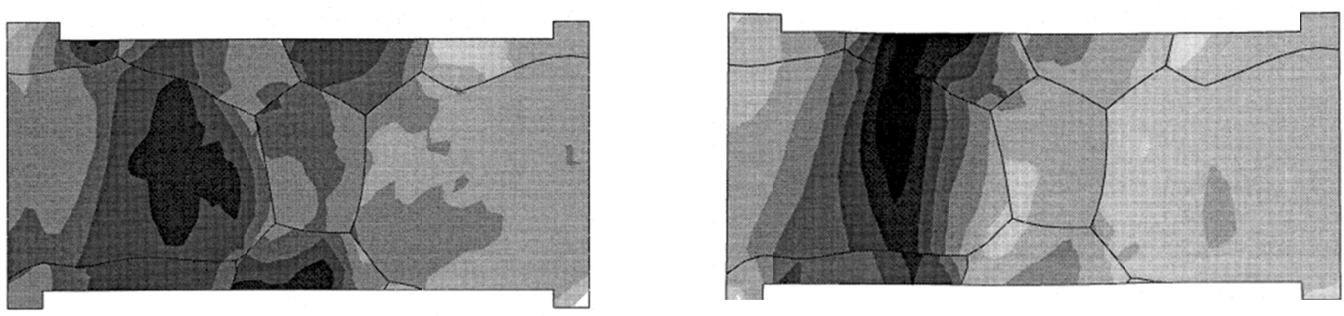
Fig. 9. Distribution of axial strain in a tensile specimen in copper tested at room temperature (higher strains are darker), a) $7.5 \%$ strain, b) $33 \%$ strain, as measured in [88].

\subsection{Extending Stacking Faults}

Under various circumstances (stress increase, temperature decrease, segregation, etc.) the separation between leading and trailing Shockley partials may increase, leading to an extended stacking fault (ESF) that can sometimes run through the entire grain as observed in Fig. 10. ESF are generally observed in pure elements and alloys with low SFE (e.g., [89,90,91]), such as 304 and 316 stainless steels.

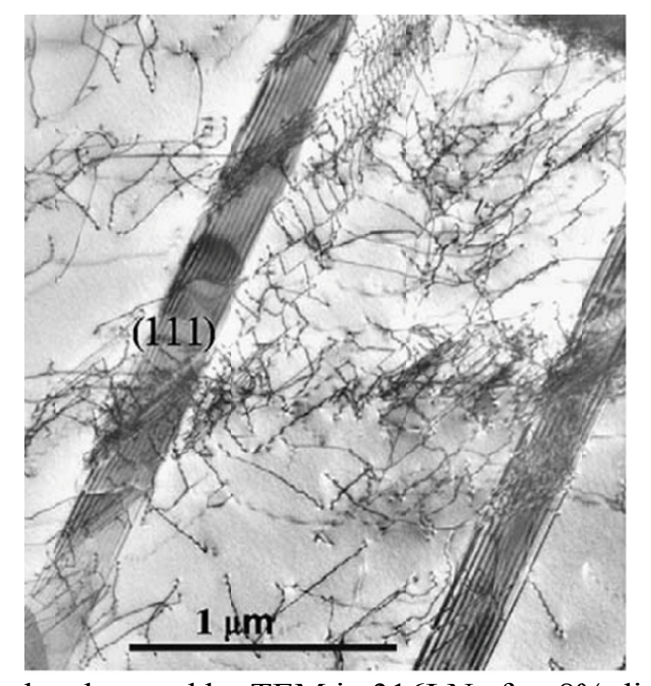

Fig. 10. Extended stacking faults observed by TEM in $316 \mathrm{LN}$ after $8 \%$ disk-bend deformation at $150^{\circ} \mathrm{C}$, from $[91]$.

ESF formation can be evaluated through Eq. (5), reproduced from Byun [20]. The equation gives the width of a stacking fault on a $\{111\}$ plane under a shear stress $(\tau)$, assuming the dislocation lines are all perpendicular to the direction of $\tau$, with: $b=$ modulus of the Burgers vector of the Shockley partials, $G=$ shear modulus, $\gamma=$ SFE, $\theta_{1 / 2}=$ angle between the Burgers vectors of the leading/trailing partial and the dislocation lines, $v=$ Poisson's ratio. This equation predicts that the shear stress can increase the width of the stacking fault. A more general model with no assumption on the angle between the dislocation line and the direction of $\tau$ is derived in [21].

$w=\frac{G b^{2}}{\pi\left(2 \gamma-\tau b\left|\sin \theta_{2}-\sin \theta_{1}\right|\right)}\left(\cos \theta_{1} \cos \theta_{2}+\frac{\sin \theta_{1} \sin \theta_{2}}{1-v}\right)$

The most important outcome from Eq. 5 is that the width between leading and trailing partials increases and may go to infinity (i.e., grain size) with increasing shear stress or decreasing SFE, leading to the formation of an ESF. The stress has a maximum influence on the width of the stacking fault when the perfect dislocation is screw $\left(\theta_{1}=30^{\circ}\right.$ and $\left.\theta_{2}=-30^{\circ}\right)$. In this case, Eq. 6 gives the critical resolved shear stress necessary to form an infinitely large stacking fault.

$\tau_{c}^{E S F}=2 \gamma / b$

Fig. 11 shows the effect of the tensile stress on stacking fault width calculated by Talonen and Hänninen [40] using Byun's model, and considering a perfect screw dislocation and the maximum possible Schmid factor of 0.5 and two different SFE representative of 304 and $301 \mathrm{LN}$ steels. The plot shows that the width of the fault diverges at tensile stresses of $480 \mathrm{MPa}(304$ steel) and $340 \mathrm{MPa}$ (301LN steel). Those values are in good agreement with experimental results. It can be noticed that the 
critical tensile stress is very sensitive to the SFE. Thus, slight chemical or temperature variations may induce large effect on the plastic behavior. It should be also mentioned that only slip systems for which the Schmid factor is higher on the leading than on the trailing partial are expected to lead to the formation of ESF (see Table 1) [92], which is implicitly captured in Byun's model. For the other systems, the stress reduces the stacking fault width.

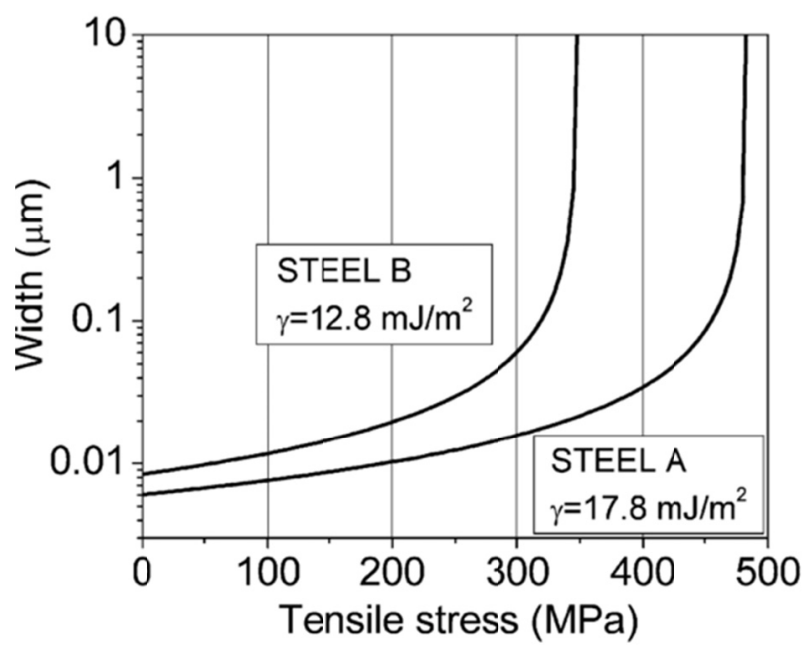

Fig. 11. Effect of tensile stress on the width of stacking faults for an AISI 304 (Steel A) and AISI 301LN (Steel B), from [40].

Eq. (5) is very useful for qualitative understanding of the formation of large stacking faults, and thus of twins and martensite, but cannot be used for quantitative prediction. For instance, in a $<111>$ crystal, using the exact value of the Schmid factor for the only configuration where the shear stress can separate partials $\left(\cos \phi=0.3\right.$ and $\theta_{1}=30^{\circ} / \theta_{2}=90^{\circ}$ ) leads to a prohibitively high critical tensile stress for stacking fault divergence in 304 and 316 steels, as shown in Fig. 12. However, ESF are observed in $<111>$ grains of both steels (e.g., [58]).

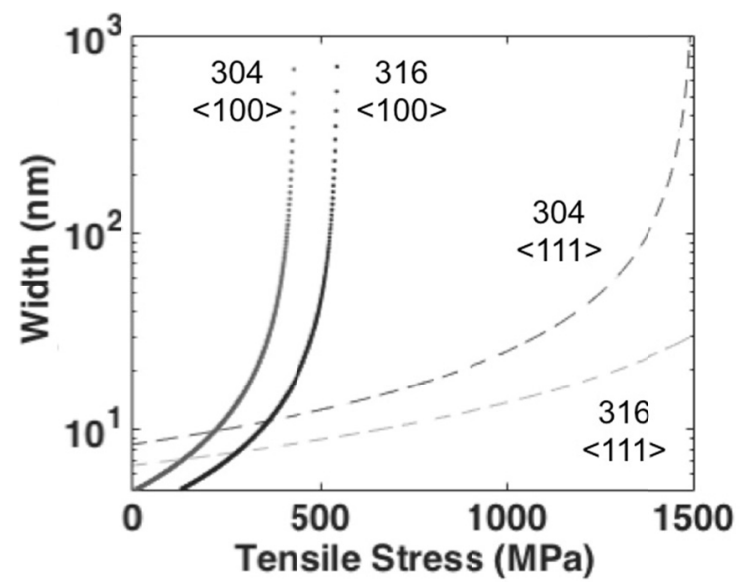

Fig. 12. Stress dependence of stacking fault width calculated from Eq. (5) for two different grain orientations in $304\left(\mathrm{SFE}=17 \mathrm{~mJ} / \mathrm{m}^{2}\right)$ and $316\left(\mathrm{SFE}=25 \mathrm{~mJ} / \mathrm{m}^{2}\right)$ steels, with $G=65.6 \mathrm{GPa}, v=0.28, b$ $=0.145 \mathrm{~nm}$.

Besides analytical models, TEM in situ straining studies provided key insights on ESF formation. In particular, Fujita and Ueda [9] showed that elastic interactions between dislocations could reduce the required critical stress for this formation compared to the aforementioned model. Fig. 13 shows 
that interaction between two dislocations with opposite Burgers vectors slipping on two closely spaced parallel $\{111\}$ planes ease the formation of two ESF. TEM experiment also revealed that once an ESF has been formed, slip systems on planes close to the faulted plane are easily activated and form overlapping ESF [93]. As discussed in Paragraphs 2.5 and 2.6, this phenomenon very likely contributes to the stress-induced formation of twins and $\varepsilon$-martensite, and was analytically modeled in [40].

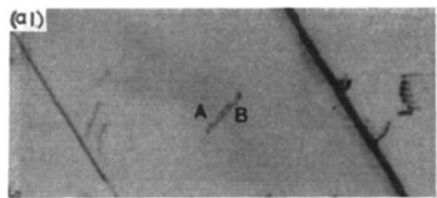

a)

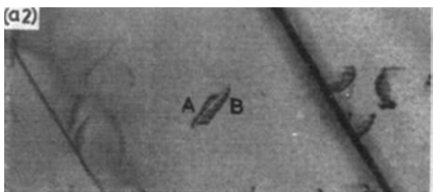

b)

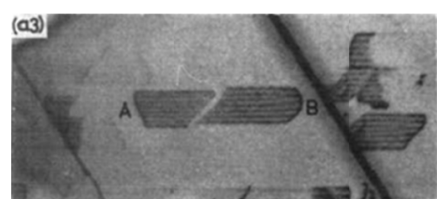

c)

Fig. 13. Formation of ESF eased by elastic interaction between two dislocations (A and B) in 304 steel. Observation made in TEM, the stress has been applied by focusing the electron beam, from [9].

\subsection{Dynamic Strain Aging and Portevin-Le Châtelier effect}

Dynamic strain aging (DSA) is an atomic-scale phenomenon responsible for unstable plastic flow. It is macroscopically observed as serrations on the tensile curve known as the Portevin-Le Châtelier effect (PLC) $[94,95,96]$ (see Fig. 14), and negative strain rate sensitivity of the flow stress (e.g., [97]). A consensus on the DSA mechanism in austenitic steels has not yet been reached, even for austenitic stainless steels as reviewed in [98]. One often proposed mechanism [99,100,101] involves interstitial or substitutional atoms diffusing to dislocations and constituting atmospheres around their cores, therefore impeding dislocation motion. With increasing applied load, the local stress reaches a threshold that allows dislocations to break free from their atmosphere or multiply themselves, or both, for instance through a multiple-cross-slip mechanism. Because of the increase in the number of mobile dislocations, deformation is easier and the load drops, until atmospheres are formed again, and so on. In variants of this mechanism for austenitic steels, the blocking of dislocations involves the reorientation hop of $\mathrm{C}$ - or $\mathrm{N}$-vacancy complexes that minimize their elastic interaction with nearby dislocations [102], or the formation of short-range order by formation of C-Mn or N-Cr pairs which increases the friction stress [103].

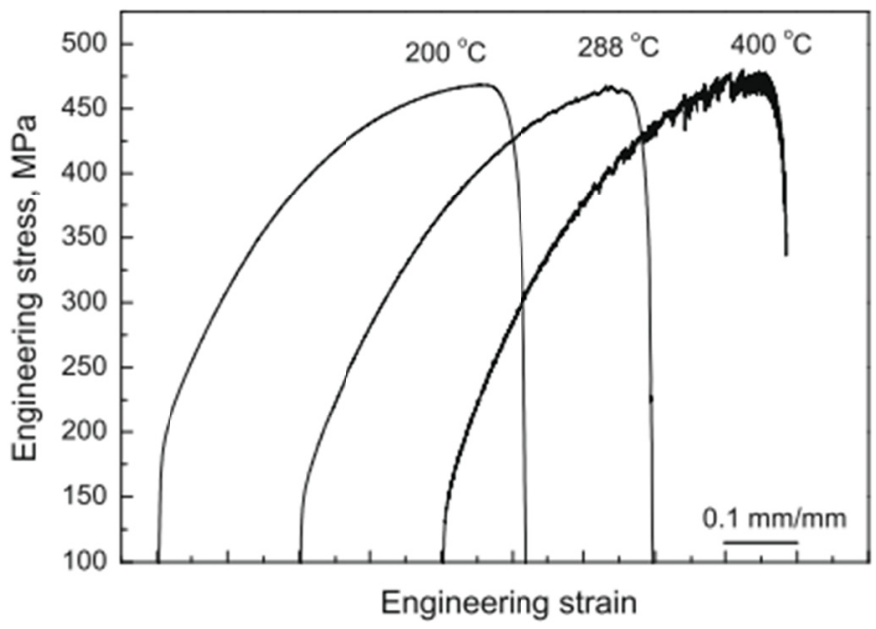

Fig. 14. Stress-strain curves of AISI $316 \mathrm{NG}$ steel tested at $10^{-5} \mathrm{~s}^{-1}$ and showing serrated behavior at 288 and $400{ }^{\circ} \mathrm{C}$, from [96].

The serrations observed experimentally are due to strain localization in regions called PLC bands. Although PLC bands typology and behaviors have been extensively studied experimentally (see review in [104]), the transition from DSA (involving dislocations individually) to band nucleation 
(involving dislocations collectively) is still not well understood. Some kind of synchronization of dislocation nucleation, multiplication, and propagation is required [105], which is likely controlled by dislocation long-range interactions [106,107,108].

DSA requires a temperature sufficiently high to activate the diffusion-based dislocation blocking mechanism but not as high as to make thermal energy overcome elastic interaction energies or dissolve point defect complexes. Also, dislocation velocity has to roughly match atom or vacancy migration speed. Consequently, DSA appears in a narrow domain of temperature / strain rate, or in two domains (low and high temperature domains) when the involved diffusing atoms change with temperature. In austenitic stainless steels, PLC is observed from about 250 to $600^{\circ} \mathrm{C}$ with strain rates between $1 \times 10^{-4}-1 \times 10^{-2} \mathrm{~s}^{-1}$ as shown in Fig. 15. The involved diffusing atoms are believed to be $\mathrm{C}, \mathrm{N}$ or $\mathrm{Ni}$ in the lower temperature range $\left(250\right.$ to $\left.400^{\circ} \mathrm{C}\right)$, and substitutional atoms such as $\mathrm{Cr}$ in the higher temperature range $\left(400\right.$ to $\left.600^{\circ} \mathrm{C}\right)[96,109,110]$. In Fe-Mn-C and Hadfield austenitic steels, PLC was reported down to $-25^{\circ} \mathrm{C}[50,111,112]$ for a strain rate of about $10^{-4} \mathrm{~s}^{-1}$. Diffusion of involved species along dislocation lines was suggested to explain PLC at so low temperatures (e.g., [112,113]). Although DSA is often attributed to $\mathrm{N}$ atoms, some experimental results $[114,115,116]$ tend to show that $\mathrm{N}$ restricts the size of the DSA domain by shifting its lower temperature bound to higher temperatures. On the contrary, it has been observed that pre-straining tends to favor DSA $[98,116]$.

Several authors suggested that DSA can significantly impact tensile and fatigue properties of austenitic steels. In Fe-Mn-C austenitic steels, DSA increases strain hardening similarly to twinning or $\varepsilon$-martensitic transformation, although its relative importance is still controversial $[50,111]$. It was pointed out (e.g., [117,118] for 316 steels) that the minimum in ductility and the manifestation of DSA for austenitic steels occur over a similar test temperature range, as shown in Fig. 15, but the mechanism that might link DSA to ductility has not been clarified.

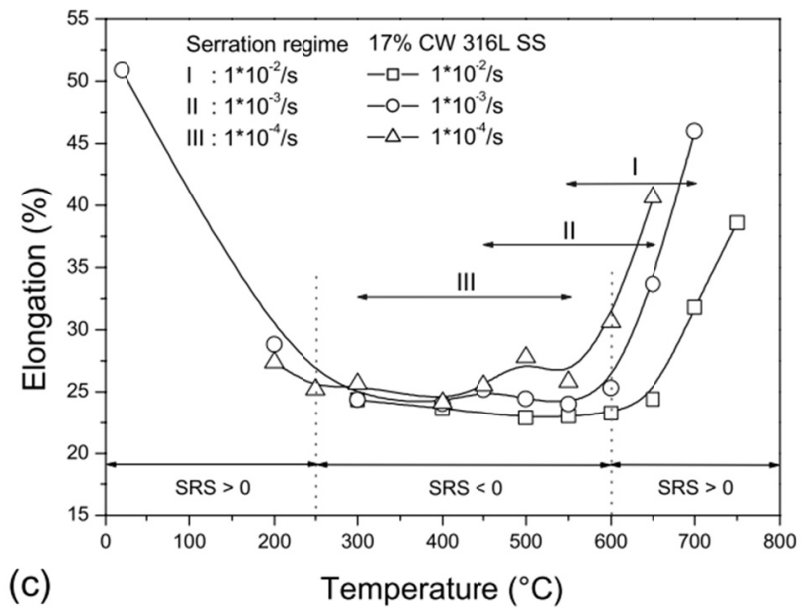

Fig. 15. Relationships between evolution of the total elongation with test temperature and occurrence of DSA during tensile test at different strain rates in $316 \mathrm{~L}$ steel. It can be noticed that as strain rate increases, both the minimum of ductility and the DSA temperature range shift to higher temperatures; SRS $>0$ : positive strain rate sensitivity, $\mathrm{SRS}<0$ : negative strain rate sensitivity (DSA domain), from [117].

\subsection{Deformation Twinning}

A twin is a defect whose lattice is related to that of the parent phase either by a reflection in some plane or by a rotation of $180^{\circ}$ about some axis [119]. This definition implies that twins are defects that have the same lattice structure as that of the parent phase, and at least one coherent interface with it (this interface is named the twinning plane). Extensive presentation of twins and twinning processes are given in several reviews, for instance [119] and [120]. In fcc crystals, different twins can appear during solidification from liquid or vapor phase (growth twins), annealing of cold worked materials 
(annealing twins) or plastic deformation under externally applied stress (deformation twins). The rest of the document considers only deformation twins.

In austenitic steels, deformation twins are very thin plates (thickness often smaller than a few 100 $\mathrm{nm}$ ), and are often named micro-twins for this reason (see Fig. 16). Several TEM studies have shown that at low strain (below about 20\%) twins are not homogeneously scattered within grains, but are rather concentrated in bundles (e.g., [121,122]). Those bundles appear like uniform bands by optical microscopy. Assessment of twin volume fraction by supposing that each band is a $100 \%$ twinned area can lead to overestimations [11].

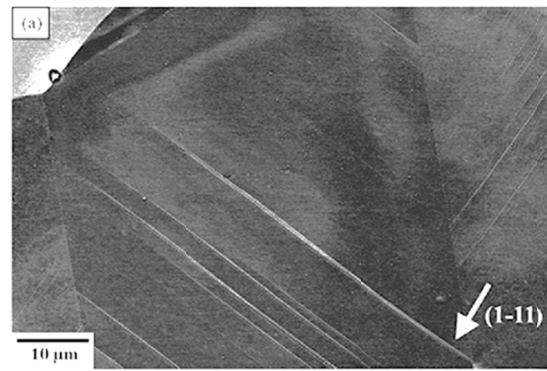

a)

Fig. 16. TEM observation of deformation twins. a) Some twins in a Fe-22Mn-0.6C steel [122]. b) A

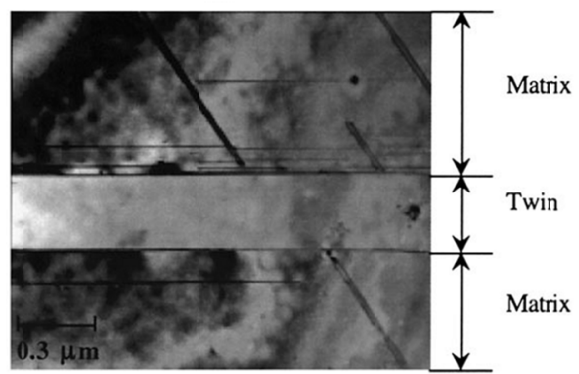

b) twin in Hadfield steel [92].

In fcc crystals, twin formation can be described by the gliding of $1 / 6<112>$ Shockley (named twinning dislocations) on each successive $\{111\}$ atomic planes. As sketched in Fig. 17, compared to the austenite structure based on a $\mathrm{ABCABC}$-type stacking of these plans, the twin can be described by a $\mathrm{ABCA} \mid \mathrm{CBAC}$-type stacking, where $\mid$ is the twinning plane. It is well accepted that twinning is a stress-assisted nucleation and growth process with critical resolved stresses for nucleation $\left(\tau_{c}^{t w-n}\right)$ and growth $\left(\tau_{c}^{t w-g}\right)$. The former stress is generally considered to be higher than the latter one. However, experimental work cannot make the distinction between the two stages, and cannot access local stress concentrations. In general, it only provides homogeneous shear stresses resulting from tensile load, named critical twinning stresses $\left(\tau_{c}^{t w}\right)$, from which twins are observed. A few key experimental results regarding $\tau_{c}^{t w}$ and the critical tensile stress $\sigma_{c}^{t w}$ are listed below:

- Some studies suggested a linear or square root dependence of $\tau_{c}^{t w}$ with SFE [123]. This result can be paralleled with the fact that high-SFE fcc materials (e.g., Ni with SFE of $110 \mathrm{~mJ} / \mathrm{m}^{2}$ [53], Al with SFE of $135-200 \mathrm{~mJ} / \mathrm{m}^{2}$ [124,125]) do not exhibit twinning, except maybe in high stressed area in necking zone and at crack tip (in Ni [126,127] and Al [128]), after very high strains applied through equal-channel angular pressing on a favorable crystal orientations (in Al [129]), or in micro-indented nanocrystalline materials (in Al [130]). Very likely, for those materials the required stress level for twinning cannot be reached during regular tensile testing.

- Although some measurements claim to show a negative or zero temperature sensitivity of $\tau_{c}^{t w}$ [123], most authors observe that twinning is favored at smaller temperatures. This indicates positive temperature sensitivity for $\tau_{c}^{t w}$, often attributed to the positive SFEdependence of $\tau_{c}^{t w}$ [131].

- Several authors noticed that $\sigma_{c}^{t w}$ increases as the grain size decreases, according to a Hall Petch-type relationship: $\sigma_{c}^{t w}=\sigma_{0}^{t w}+k_{T} d^{-1 / 2}[122,123,132,133]$. It was pointed out that $k_{T}$ is significantly larger than $k_{S}$ for slip in the Hall-Petch formula for yield stress [123,132]. As explained below, the dependence on $d^{-1 / 2}$ may be interpreted with twin nucleation models requiring stress concentration through dislocation pile-ups, of which the maximum length decreases with grain size. Some authors reported an inhibition of twinning for grain sizes below $3 \mu \mathrm{m}[122,134]$. However, in nanograins (as observed on 10-15 nm grain in Al [130] or on grains smaller than $0.5 \mu \mathrm{m}$ in 301LN steels [135]), twinning may become prevalent over slip because of a relatively smaller critical nucleation stress for partial dislocation than for perfect dislocation. 
- Most authors agree that increasing strain rate decreases $\tau_{c}^{t w}$ and then favors twinning over slip. However, the strain rate effect depends on the considered range of variation, as explained in Paragraph 2.7.2.

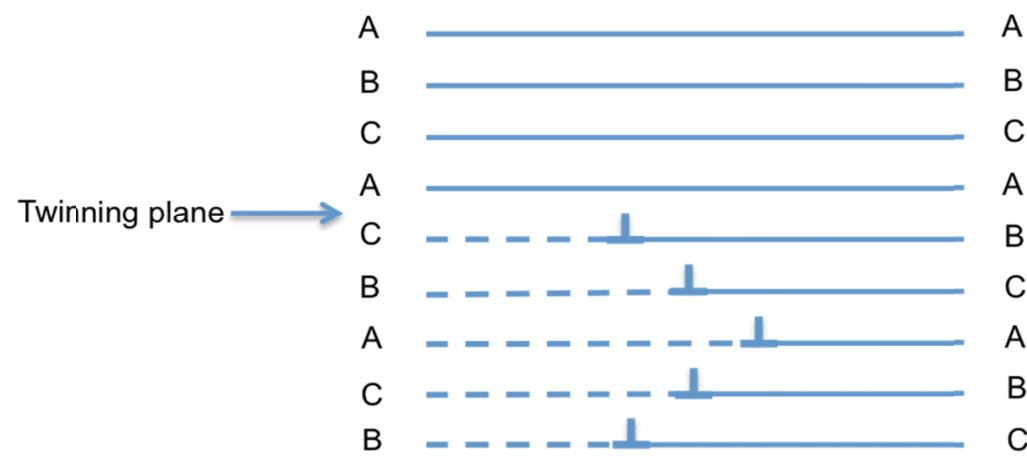

\section{$\perp$ Shockley partial dislocation}

\section{- - Twinned crystal}

Fig. 17. Sketch illustrating twinning in an fcc matrix.

Unlike experimental work, theoretical approaches can distinguish twinning nucleation $\left(\tau_{c}^{t w-n}\right)$ from growth $\left(\tau_{c}^{t w-g}\right)$. Some key results are discussed hereafter.

Nucleation: There is no clear depiction of twin nucleus, but they could be understood as a few small stacking faults overlapping on adjacent $\{111\}$ planes. According to ab-initio simulations, two or three faults are enough to define a stable twin nucleus in fcc crystals [51,53]. Such overlapping can statistically exist in dislocation networks, even in annealed steels [61]. However, a large number of models about the formation of twin nuclei have been put forward in the last 50 years to explain the observed high volume fractions of twins (see reviews in $[119,120])$. There is no consensus on the validity of those models, despite TEM studies aimed at revealing them (e.g., [136]).

It is likely that twin nucleation is heterogeneous (relying on defects rather than occurring in a perfect crystal), and is initiated from pre-existing dislocation configurations. Most proposed nucleation mechanisms (e.g., $[92,123,137,138,139])$ require a high local stress $\left(\tau_{c}^{t w-n}\right)$ that can be reached only through stress concentrations, obtained for instance around inclusions or through dislocation pile-ups. Pile-up models can easily explain why twins are often generated on grain boundaries, which are efficient barriers to dislocation gliding. Many experimental studies have confirmed that slip is required for activating twinning (see review [119]). More precisely, several authors reported that multiple slip is necessary (e.g., $[122,136,138])$.

In most models, $\tau_{c}^{t w-n}$ is proportional to $\frac{\gamma}{b}$ with $\gamma$ the SFE and $b$ the module of the Burgers vector of the partial dislocations [11,58,138]. However, as shown in Fig. 18, Kibey et al. [53] predicted through first principle analysis that the critical stress for nucleation is better correlated to the unstable stacking fault energy $\left(\gamma_{\mathrm{ut}}\right)$ than to the SFE $\left(\gamma_{\text {isf }}\right.$ in Fig. 18). Both energies characterize the energy pathways associated with twinning, also called the generalized planar fault energy. 


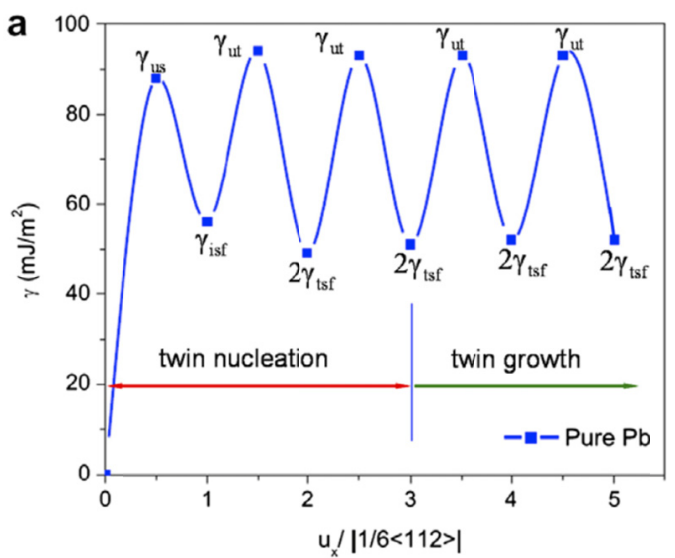

a) Generalized planar energy fault for pure $\mathrm{Pb}$ vs. shearing on successive $\{111\}$ planes along $\mathrm{a}<112>$ direction. $\gamma_{\mathrm{us}}=$ stacking fault nucleation barrier, $\gamma_{\text {isf }}=$ intrinsic one-layer fault energy (SFE), $\gamma_{\mathrm{ut}}=$ twin nucleation barrier, $2 \gamma_{\text {tsf }}=$ coherent twin boundary energy.

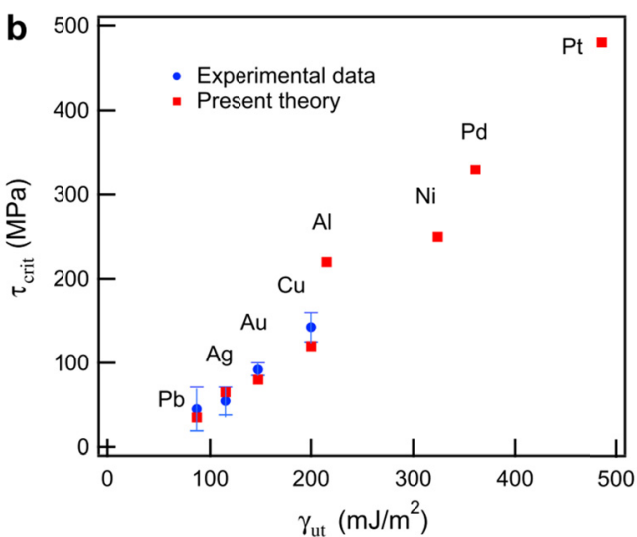

b) Correlation between the critical stress for twin nucleation (named $\tau_{c}^{t w-n}$ in the text) and $\gamma_{\mathrm{ut}}$ the twin nucleation barrier for several pure fcc metals.

Fig. 18. Prediction of the critical stress for twin nucleation through first principle analysis, from [53].

Growth: Growth models suppose that a twin nucleus is pre-existing. Talonen and Hänninen [40] modeled the growth process by considering a nucleus composed of $\mathrm{N}$ stacking faults overlapping on successive $\{111\}$ planes, and bordered on each side by an array of $\mathrm{N}$ partial dislocations. Considering a situation without any external stress, Eq. (4) was used to derivate Eq. (7), which gives the nucleus width.

$\mathrm{w}=\frac{\mathrm{NGb}^{2}}{2 \pi(2 \lambda)}\left(\cos \theta_{1} \cos \theta_{2}+\frac{\sin \theta_{1} \sin \theta_{2}}{1-v}\right)$

For $2 \lambda=15 \mathrm{~mJ} / \mathrm{m}^{2}, G=65.6 \mathrm{GPa}, b=0.145 \mathrm{~nm}, v=0.3$, and screw dislocations $\left(\theta_{1}=-\theta_{2}=30^{\circ}\right)$, Eq. (7) predicts that the width of the twin is about $N \times 12 \mathrm{~nm}$. This equation shows that the twin gets wider as it gets thicker, but its width will not diverge unlike for ESF. Thus, grain-wide twin growth needs stress assistance. Byun [20] supposed that when the width of one stacking fault in a twin nucleus diverges under shear stress, the stress required for additional gliding of twinning dislocations from the same nucleus is lowered, as experimentally observed by Fujita and Ueda [9]. Therefore, he considered that the critical resolved shear stress for twinning growth is the same as the one given by Eq. (6): $\tau_{c}^{t w-G}=2 \gamma / b$. The increase in thickness from a few layers to the observed tens or hundreds of layers is not well understood. Mahajan and Chin [140] postulated that twin thickening is due to three-layer nuclei combining and agglomerating. Furthermore, first principle simulations showed that from an energy standpoint, it is easier to thicken a twin from $n$ to $n+1$ layers, than to nucleate it from 0 to 2 [51].

Twinning characteristics: plenty of experimental data on austenitic steel single or poly-crystals (e.g., $[122,137,141,142])$ reveal that twinning at low strain is strongly grain-orientation dependent. Twinning is favored in $<111>$ grains (with a $<111>$ direction close to the tensile axis), as shown in Fig. 19a. This can be explained by assuming that twinning occurs when some leading partials have a Schmid factor simultaneously greater than 1) the Schmid factor of the corresponding trailing partials (to extend stacking faults [20]), and 2) the maximum Schmid factor of perfect dislocations (to favor twinning over slip, assuming equal critical resolved shear stress for slip and twinning [122]). Both criteria lead to defining one region in the standard stereographic triangle where twinning is possible, as shown in Fig. 20. Moreover, activation of multiple slip systems is required, which is mainly met in $<111>$ grains, and to a smaller extent in $<100>$ grains, at low strains. Intersecting the three criteria leads to predict twinning at low strain only in $<111>$ grains. At high strain, due to grain rotation (see 
Section 4), most grains become orientated along the $<100>-<111>$ segment of the stereographic triangle, among which $<111>$ grains show more twins Fig. $19 \mathrm{~b}$.

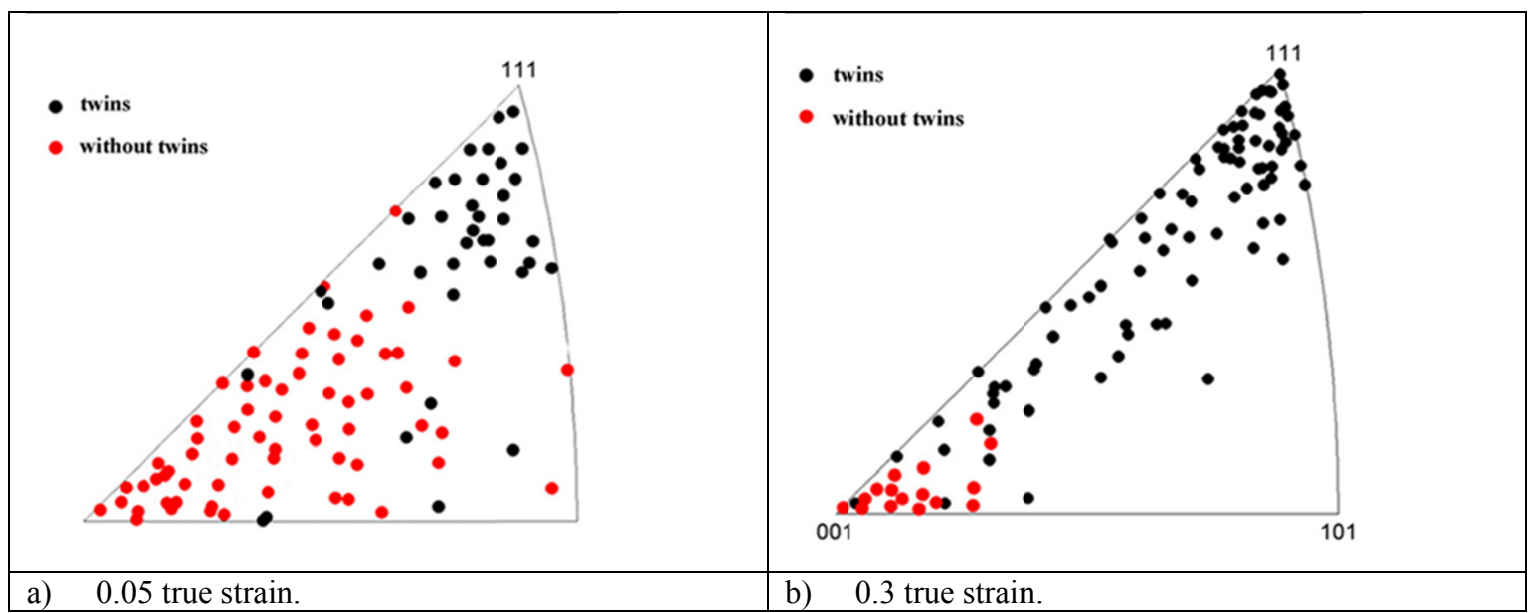

Fig. 19. Grain orientation dependence of twinning in an Fe-Mn type steel after tensile straining, from [122]. Similar results were obtained on a 304 austenitic stainless steel in [13].

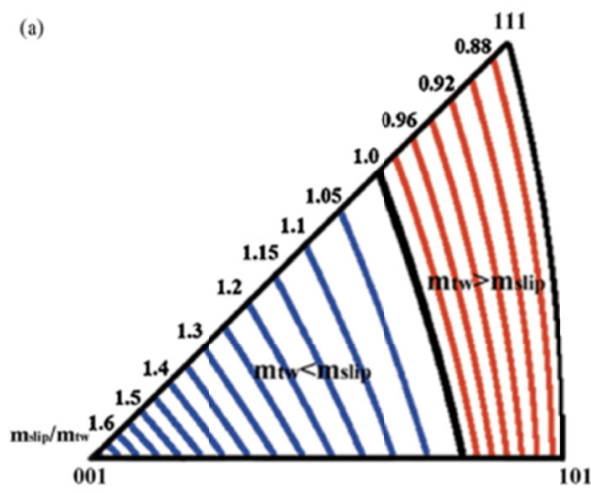

Fig. 20. In red, domain where leading partials have a Schmid factor $\left(\mathrm{m}_{\mathrm{tw}}\right)$ simultaneously greater than 1) the Schmid factor on corresponding trailing partials, and 2) the maximum Schmid factor of perfect dislocations $\left(\mathrm{m}_{\text {slip }}\right)$. In blue, domain where all the leading partials have a Schmid factor lower than the highest Schmid factor on perfect dislocations, from $[58,122]$.

At high strain, at least two twin systems (among the 12 possible variants) are generally sequentially activated in each grain. Several authors (e.g., [11,143]) have experimentally observed that the first activated system is the one with the highest Schmid factor on the leading partial. Then, due to strain hardening and grain rotation, the resolved shear stress on a second system can reach the critical value to activate twinning. Because twins have difficulties crossing each other, a ladder-type structure is observed. In some grains, two twin systems may have about the same Schmid factor and be simultaneously activated during the test, which leads to an ear-type structure [11]. Both cases are sketched in Fig. 21. 


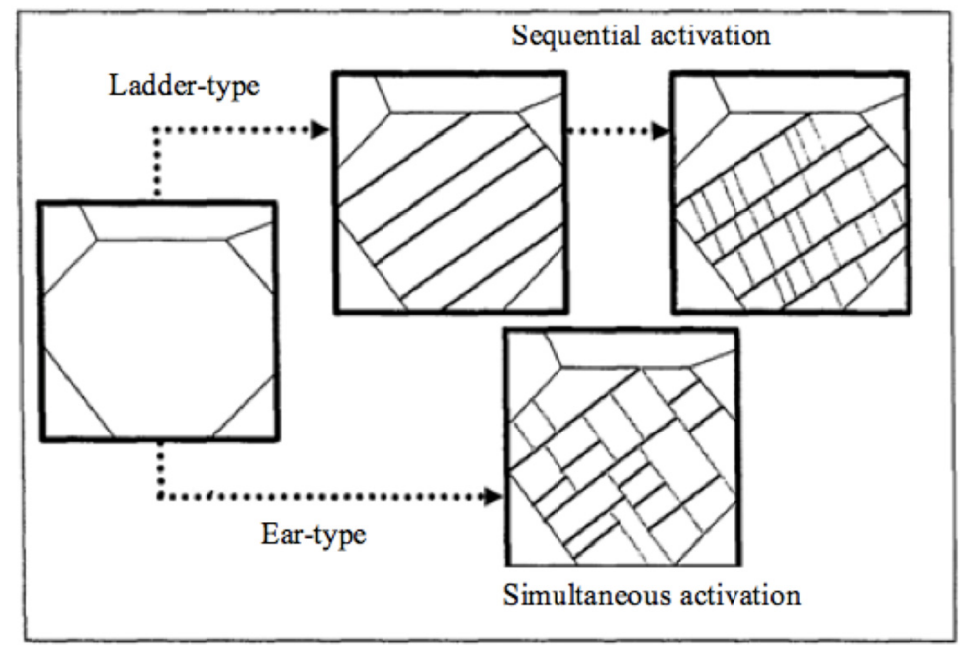

Fig. 21. Formation of twins by activation of two twinning systems operating either successively (different Schmid factor at test start), leading to a ladder-type structure, or simultaneously (about the same Schmid factor at test start), leading to an ear-type structure [11].

It was shown that the twin volume fraction in austenitic steels increases with strain according to a sigmoidal law $[11,121,144,145]$. Twin volume fraction saturation values depend on steels and experimental condition (strain rate), but are likely in the tens of percent $[11,92]$.

It was noticed that dislocation glide occurs mainly in the un-twinned region of twinned grains (see Fig. 22), which may be explained by two reasons: 1) twin/matrix interfaces are very strong obstacles for matrix dislocations, although a few dislocations do penetrate twin [146], and 2) existing matrix dislocations become sessile in twinned zone and act as forest dislocations, which explains that twins are $35-40 \%$ harder than matrix in $35 \%$ strained Hadfield steel according to [92].

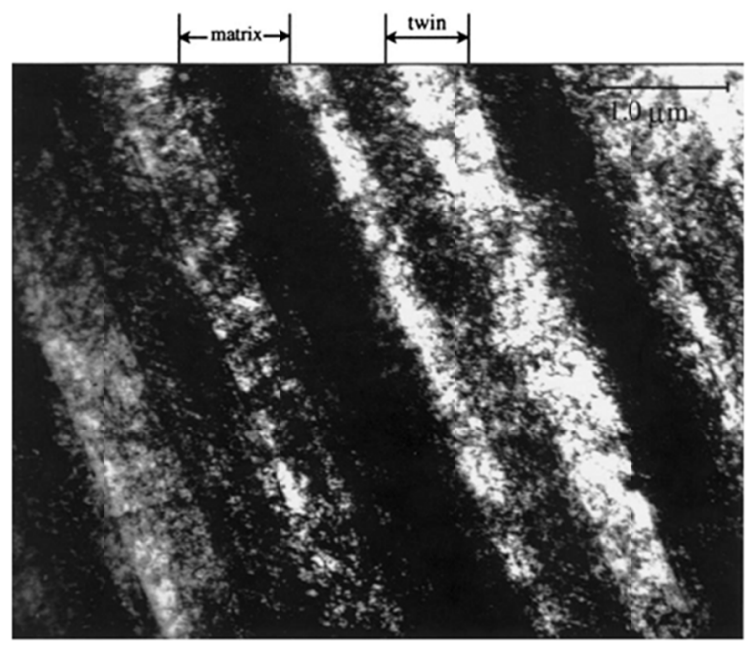

Fig. 22. TEM micrograph of a $<111>$ Hadfield steel single crystal deformed under tension at room temperature (strain: $35 \%$ ). Dislocation activity is more significant in the matrix than in the twinned region [92].

Deformation twinning induces a shearing of the austenite phase. The shear strain induced by one twin equals $b / d_{111}=1 / \sqrt{2}$, where $d_{111}$ is the reticular distance of $\{111\}$ planes, and $b$ is the module of the Burgers vector of a Shockley partial. The contribution of twinning to elongation at rupture is small [147]. If a single crystal twins entirely, the induced elongation cannot exceed $35 \%$, depending on the initial orientation. For a $40 \%$-twinned random polycrystal, the elongation due to twinning is maximum $12 \%$. 
Even though the strain contribution from twinning is small, it is well admitted that twinning contributes to the impressive elongations of several alloys (e.g., TWIP steels). This is attributed to the hardening produced by twins acting as strong obstacles to dislocation gliding. Twin volume faction increases during test, which results in a dynamic Hall-Petch effect [148] (i.e., sustained hardening) that postpones necking in accordance with the Considère criteria (e.g., [10]). According to Allain [11], significant dynamic Hall-Petch effect only happens when the second twinning system is activated. The primary twinning system is expected to have a weak hardening effect because its twinning plans are parallel to the slip plans of the primary slip system.

\subsection{Formation of Martensite}

\subsubsection{Overview}

Austenitic steels may be subject to martensitic transformation - a phase transformation without diffusion, also termed displacive transformation - in which parent (fcc) and formed phases keep crystallographic relationships. Two types of martensite can be formed in austenitic steels: $\varepsilon$-martensite with a hexagonal-closed-packed (hcp) structure, and $\alpha^{\prime}$-martensite with a body-centered-cubic (bcc) or body-centered-tetragonal (bct) structure. In absence of applied stress or defects due to pre-strain (dislocation bands, twins, or others), thermal martensite may form during cooling of the austenite below a temperature named $\mathrm{M}_{\mathrm{s}}$ (Martensite start) for $\alpha^{\prime}$-martensite and $\mathrm{E}_{\mathrm{s}}$ (Epsilon start) for $\varepsilon$ martensite. Strain and stress can induce formation of athermal martensite at temperatures above $M_{s}$ and $E_{s}$ up to maximum temperatures named $M_{d}$ (for $\alpha$ ') and $E_{d}$ (for $\varepsilon$ ). Some measurements of these temperatures are shown in Table 2. Except for cryogenic applications, only athermal martensite is expected in 304(L) and 316(L) steels.

$\mathrm{M}_{\mathrm{d}}$ and $\mathrm{E}_{\mathrm{d}}$ are usually defined by tensile testing up to a given strain or before necking (e.g., $[7,149,150])$, and thus are appropriate only for such conditions. Different deformation processes (machining, severe plastic deformation, explosion, cold-drawing, or rolling) may induce formation of martensite at temperatures higher than $\mathrm{M}_{\mathrm{d}}$ and $\mathrm{E}_{\mathrm{d}}$.

Table 2: Examples of temperatures and temperature ranges for $M_{s}, M_{d}, E_{s}$, and $E_{d}$.

\begin{tabular}{|c|c|c|c|}
\hline Alloy & $\begin{array}{l}\text { Observed } \\
\text { martensite }\end{array}$ & $\begin{array}{l}\text { Temperature below which } \\
\text { martensite appears during } \\
\text { cooling }\end{array}$ & $\begin{array}{l}\text { Maximum temperature for } \\
\text { deformation-induced martensite before } \\
\text { necking }\end{array}$ \\
\hline AISI 316 & $\begin{array}{l}\varepsilon \\
\alpha^{\prime}\end{array}$ & $\begin{array}{l}E_{s}<-196^{\circ} \mathrm{C}[151] \\
M_{s}<-196^{\circ} \mathrm{C}[151]\end{array}$ & $\begin{array}{l}-70^{\circ} \mathrm{C}[151]<\mathrm{E}_{\mathrm{d}}<200^{\circ} \mathrm{C}[10] \\
-196^{\circ} \mathrm{C}[10]<\mathrm{M}_{\mathrm{d}}<-70^{\circ} \mathrm{C}[151]\end{array}$ \\
\hline AISI 304 & $\begin{array}{l}\varepsilon \\
\alpha^{\prime}\end{array}$ & $\begin{array}{l}-78^{\circ} \mathrm{C}[152]<\mathrm{E}_{\mathrm{s}}<20^{\circ} \mathrm{C} \\
\mathrm{M}_{\mathrm{s}}<-269^{\circ} \mathrm{C}[152]\end{array}$ & $\begin{array}{l}\mathrm{E}_{\mathrm{d}} \approx 20^{\circ} \mathrm{C}[40,152] \\
50^{\circ} \mathrm{C}[153]<\mathrm{M}_{\mathrm{d}}<80^{\circ} \mathrm{C}[150]\end{array}$ \\
\hline Fe-15.9Cr-12.5Ni-0.01C & $\begin{array}{l}\varepsilon \\
\alpha^{\prime}\end{array}$ & $\begin{array}{l}E_{s}=-95^{\circ} \mathrm{C}[7] \\
M_{s}=-95^{\circ} \mathrm{C}[7]\end{array}$ & $\begin{array}{l}\mathrm{E}_{\mathrm{d}}=-10\left( \pm 20^{\circ} \mathrm{C}\right)[7] \\
\mathrm{M}_{\mathrm{d}}=80^{\circ} \mathrm{C}[7]\end{array}$ \\
\hline Fe-15.7Cr-11.2Ni-0.1C & $\alpha^{\prime}$ & $\mathrm{M}_{\mathrm{s}}<-269^{\circ} \mathrm{C}[7]$ & $\mathrm{M}_{\mathrm{d}}=60^{\circ} \mathrm{C}[7]$ \\
\hline
\end{tabular}

Stability of martensite with respect to austenite (and accordingly $\mathrm{M}_{\mathrm{s}}, \mathrm{E}_{\mathrm{s}}, \mathrm{M}_{\mathrm{d}}$ and $\mathrm{E}_{\mathrm{d}}$ ) depends on chemical composition. Several formulas have been developed from regression analysis of experimental data to calculate these temperatures (see examples in [154]). For instance, for the ranges of composition relevant to the 300 series of austenitic stainless steels, [155] proposed a formula for $\mathrm{M}_{\mathrm{s}}$ and $\mathrm{M}_{\mathrm{d}}$, and [156] proposed a formula for $\mathrm{E}_{\mathrm{s}}\left(\mathrm{M}_{\mathrm{d} 30}\right.$ is defined as the temperature at which $50 \%$ of $\alpha^{\prime}-$ martensite is formed by a true strain of $30 \%$; the alloying elements are in weight $\%$.):

- $\mathrm{M}_{\mathrm{s}}\left({ }^{\circ} \mathrm{C}\right)=502-810 \mathrm{C}-1230 \mathrm{~N}-13 \mathrm{Mn}-30 \mathrm{Ni}-12 \mathrm{Cr}-54 \mathrm{Cu}-46 \mathrm{Mo}$

- $\mathrm{M}_{\mathrm{d} 30}\left({ }^{\circ} \mathrm{C}\right)=497-462(\mathrm{C}+\mathrm{N})-9.2 \mathrm{Si}-8.1 \mathrm{Mn}-13.7 \mathrm{Cr}-20 \mathrm{Ni}-18.5 \mathrm{Mo}$

- $\mathrm{E}_{\mathrm{s}}\left({ }^{\circ} \mathrm{C}\right)=374-710.5(\mathrm{C}+1.4 \mathrm{~N})-18.5 \mathrm{Ni}-12.4 \mathrm{Mn}-8.4 \mathrm{Cr}+13.4 \mathrm{Si}-1.6 \mathrm{Mo}-22.7 \mathrm{Al}+$ $11.6(\mathrm{C}+1.4 \mathrm{~N})(\mathrm{Mo}+\mathrm{Cr}+\mathrm{Mn})-3.7[(\mathrm{Ni}+\mathrm{Mn})(\mathrm{Cr}+\mathrm{Mo}+\mathrm{Al}+\mathrm{Si})]^{1 / 2}$ 
Formulas are usually linear weighted sums of alloying compositions, with sometimes non-linear terms or binary interaction terms. Since the early 2000 s, more refined approaches have been implemented, such as the use of a thermodynamic model to predict $\mathrm{M}_{\mathrm{s}}$ from chemical composition [157]. Recent progress was also made in $[158,159,160]$, thanks to approaches based on Bayesian Neural Networks trained on experimental data.

Several studies, e.g., $[161,162]$, have shown that $\mathrm{M}_{\mathrm{s}}$ and $\mathrm{E}_{\mathrm{s}}$ decrease as austenite grain size decreases, which led to conclude that grain size (or thermal treatment conditions) should be included in $\mathrm{M}_{\mathrm{S}}$ and $\mathrm{E}_{\mathrm{S}}$ predictive approaches. Some authors [161] explained this dependence by a reduction of nucleation rate and branching of martensite plates in smaller grains. Other authors [154,163] claimed that the noticed grain size effect is an experimental artifact, because of martensite platelets being less detectable by dilatometry in smaller grains (since platelets are smaller more platelets are required for detection).

Both types of martensite restrain mobility of dislocation in austenite, and, furthermore, are much harder than the latter [164]. Their formation during tensile test contributes to work hardening, which might delay necking on test specimens and increase elongation in accordance with the Considère criteria [165]. It is used to impart impressive elongations to several types of alloys (e.g., TRIP steels). However, to meet this objective the transformation has to be progressive and sustained as long as possible during the tensile test. Necking usually occurs shortly after the transformation stops.

During tensile straining, the volume fractions of $\varepsilon^{-}$and $\alpha^{\prime}$-martensite continuously evolve. In tests on 304 [152] and 316 [151] steels at $-196^{\circ} \mathrm{C}$, it was shown that the volume fraction of $\alpha$-martensite increases continuously, while the volume fraction of $\varepsilon$ - martensite reaches a maximum at $10-15 \%$ and then decreases. Other results on 304 steels at $-60^{\circ} \mathrm{C}$ [166] and $20^{\circ} \mathrm{C}$ [167] (see Fig. 23) show a similar trend. In all tests, the decline of $\varepsilon$-martensite is likely due to an $\varepsilon \rightarrow \alpha$ ' transformation, described in Paragraph 2.6.3.

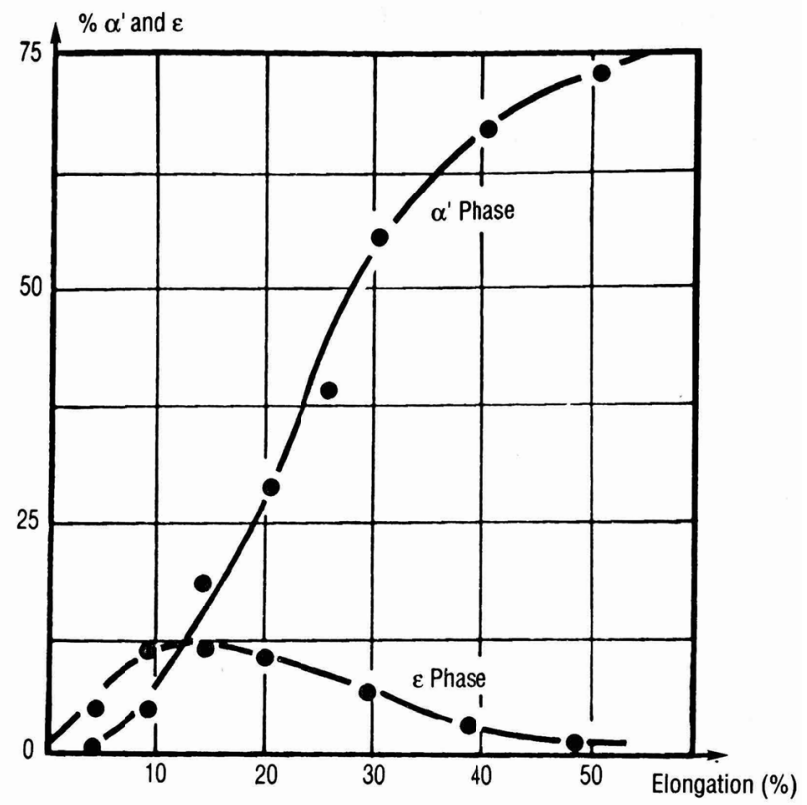

Fig. 23. Variation of volume fraction of $\varepsilon$ - and $\alpha^{\prime}$-martensite during tensile strain in 304 steel at $20^{\circ} \mathrm{C}$, reproduced from [168], data from [167].

\subsection{2 $\varepsilon$-martensite}

$\varepsilon$-martensite appears as very thin plates or lenses (typically with a thickness of about 100 and 10 $\mathrm{nm}$ in $304 \mathrm{~L}$ steel when formed at $-196^{\circ} \mathrm{C}$ and $20^{\circ} \mathrm{C}$, respectively [164]). The closed-packed plane is conserved during the transformation, and the two phase are exactly or closely oriented as follows: $(111)_{\mathrm{fcc}} / /(0001)_{\mathrm{hcp}}$, and $[\overline{1} \overline{1} 0]_{\mathrm{fcc}} / /[1 \overline{2} 10]_{\mathrm{hcp}}$ or $[11 \overline{2}]_{\mathrm{fcc}} / /[1100]_{\mathrm{hcp}}$, named the Shoji-Nishiyama orientation relationships $[169,170]$. In austenitic stainless steels, the $[\overline{1} \overline{1} 0]_{\mathrm{fcc}} / /[1 \overline{2} 10]_{\mathrm{hcp}}$ is observed [46]. Lattice parameter measurements indicate that the fcc $\rightarrow$ hcp transformation is accompanied by a 
contraction of about $1 \%$ normal to the involved $\{111\}$ fcc plane $[161,171]$. Compared to the structure of austenite - $\mathrm{ABCABC}$ stacking of closed-packed atomic $\{111\}$ planes - the structure of $\varepsilon$-martensite is described as ACACAC-type stacking. As for twinning, formation of $\varepsilon$-martensite can be described by the gliding of $1 / 6<112>$ Shockley partials with parallel Burgers vectors. However, in this case the gliding occurs on every other $\{111\}$ planes, as sketched in Fig. 24. Like for twinning, it has been reported that decrease in temperature and increase in strain rate tend to favor the formation of $\varepsilon$ martensite over slip. However, the strain rate effect depends on the considered range of variation, as explained in Paragraph 2.7.2. $\varepsilon$-martensite transformation follows a nucleation and growth process.

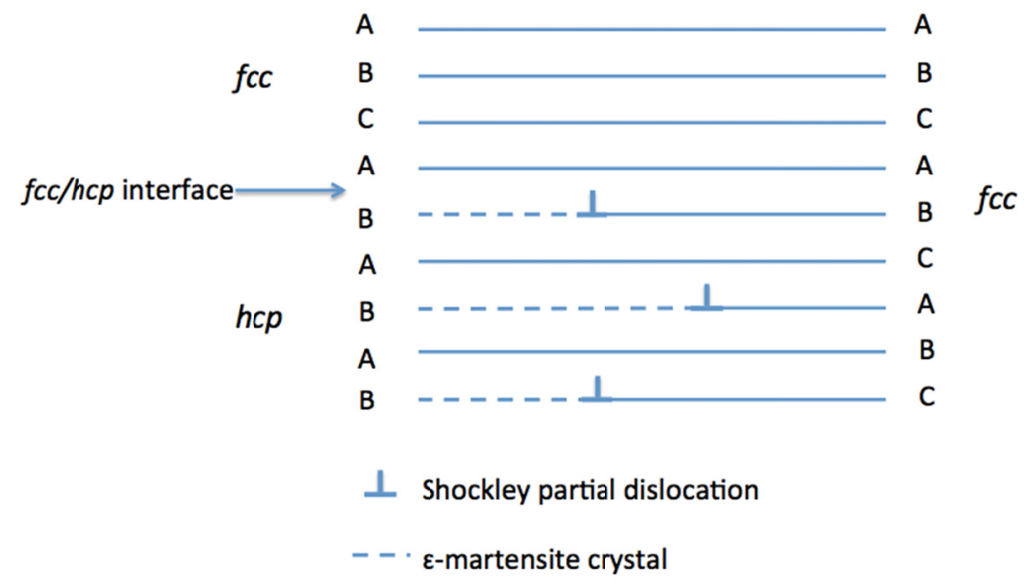

Fig. 24. Sketch illustrating the formation of $\varepsilon$-martensite in an fcc matrix.

Nucleation: there is no clear depiction of $\varepsilon$-martensite nucleus, but they could be understood as some small staking faults overlapping on every second $\{111\}$ planes. According to Olson and Cohen [61] about 7 to 10 overlapped faults are needed to get stable nucleus in $\mathrm{Fe}-\mathrm{Cr}$-Ni alloys at $\mathrm{E}_{\mathrm{s}}$, a formation that can statistically exist in dislocation networks, even in annealed materials. Under stress, $\varepsilon$-martensite nuclei are likely generated heterogeneously at the interfaces such as grain boundaries, incoherent twin boundaries, or inclusion particles $[9,61,93]$, thanks to stress concentration through mechanisms similar to those explaining the formation of twin nuclei. TEM in situ straining experiments confirmed the roles of stress concentrations and interactions between dislocations $[9,93]$. As already mentioned, those experiments showed also that a single ESF could trigger formation of a nucleus. Indeed, once an ESF is formed, the active dislocations passing on slip planes close to the fault are easily dissociated so that overlapping of stacking faults appears. They also revealed that a nucleus of $\varepsilon$-martensite can form from existing $\varepsilon$-martensite platelets through a stair-rode type cross-slip mechanism (e.g., see this mechanism in [172]).

Growth: with the same approach they used for twinning, Talonen and Hänninen [40] analyzed the growth of an $\varepsilon$-martensite nucleus formed of $N$ stacking faults overlapping on every second $\{111\}$ planes, in absence of applied stress. From Eq. (4), they established that the width of the nucleus is given by Eq. (8):

$\mathrm{w}=\frac{\mathrm{NGb}^{2}}{2 \pi(\mathrm{N}(\gamma-2 \lambda)+2 \lambda)}\left(\cos \theta_{1} \cos \theta_{2}+\frac{\sin \theta_{1} \sin \theta_{2}}{1-\nu}\right)$

Unlike for twinning (see Eq. (7)), Eq. (8) shows that when $\gamma$ is lower than $2 \lambda$, the width $w$ of the defect may diverge without any applied stress as $N$ increases, thus forming a grain-size band of $\varepsilon$ martensite. Fig. 25 shows the calculated equilibrium value of $w$ as a function of the SFE and the number of staking faults on every second plane, for $2 \lambda=15 \mathrm{~mJ} / \mathrm{m}^{2}$. The result can be paralleled with the fact that high-SFE fcc materials having $\gamma$ larger than $2 \lambda$ (e.g., Cu with SFE of $80 \mathrm{~mJ} / \mathrm{m}^{2}$ [173], Al with SFE of $135-200 \mathrm{~mJ} / \mathrm{m}^{2}[124,125]$ ) do not exhibit thermal $\varepsilon$-martensitic transformation. Of 
course, applied stress favors $\varepsilon$-martensite growth (width and thickness), very likely through the same mechanisms as for twinning.

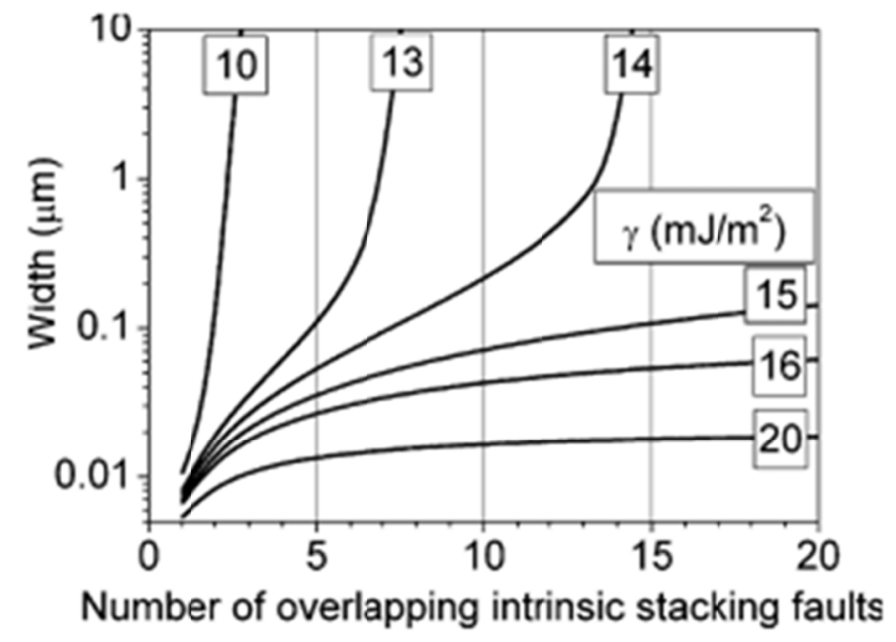

Fig. 25. Effect of SFE on equilibrium width of defects made of overlapping intrinsic stacking faults on every other $\{111\}$ plane $[40]$.

ع-martensite characteristics: as for twinning, formation of $\varepsilon$-martensite is grain orientation dependent. Fig. 26 shows that $\varepsilon$ appears mainly in grains with a $<111>$ direction close to the tensile axis [174]. The reasons of this behavior are probably the same as for twining, due to the similarities between the two mechanisms.

Deformation-induced $\varepsilon$-martensite causes a shearing equal to $b / 2 d_{111}=1 /(2 \sqrt{2})$, which is half of that of a twin. Thus, contribution of $\varepsilon$-martensite to elongation is half of the one given above for twinning, which gives at most $17 \%$ for a single grain and about $6 \%$ at rupture for a poly-crystal if $40 \%$ of the grains are fully transformed to $\varepsilon$-martensite.

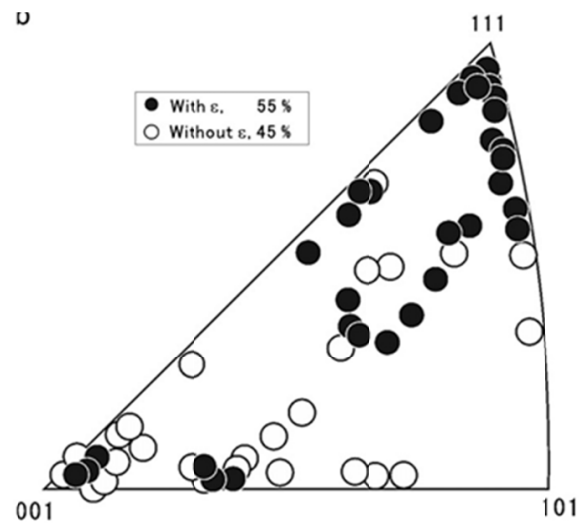

Fig. 26. Inverse pole figure showing presence $(\bullet)$ or absence $(\circ)$ of $\varepsilon$-martensite according to grain orientation with respect to the tensile axis in Fe-30Mn steel tensile strained to 29.1\%. Fractions of grains with and without $\varepsilon$-martensite are $55 \%$ and $45 \%$, respectively [174].

\subsection{3 $\alpha^{\prime}$-martensite}

$\alpha$-martensite has one of the two following orientation relationships with the austenite, depending on the steel $[152,175,176]$ : the Nishiyama relationship $(\mathrm{N}):(111)_{\mathrm{fcc}} / /(011)_{\mathrm{bcc}}$, and $[\overline{2} 11]_{\mathrm{fcc}} / /[01 \overline{1}]_{\mathrm{bcc}}$, and the Kurdjumov-Sachs relationship (K-S): $(111)_{\mathrm{fcc}} / /(011)_{\mathrm{bcc}}$ and $[\overline{1} 01]_{\mathrm{fcc}} / /[11 \overline{1}]_{\mathrm{bcc}}$. In austenitic stainless steels, the Kurdjumov-Sachs relationship is observed [46]. Formation of deformation-induced $\alpha^{\prime}$-martensite in austenitic steels during tensile test above $\mathrm{M}_{\mathrm{s}}$ has been extensively studied (e.g., 
$[7,177,178])$. For instance, experimental data [179] obtained on 304 steel at different temperatures are given in Fig. 27. They show that the volume fraction of $\alpha^{\prime}$-martensite tends to saturate at about 20 and $85 \%$ during tests run at room temperature and $-196^{\circ} \mathrm{C}$, respectively. The same authors do not report any $\alpha^{\prime}$-martensite in 316 steel for identical experimental conditions. However, deformation-induced $\alpha^{\prime}$-martensite in 316 and $316 \mathrm{~L}$ steels was observed at $-196^{\circ} \mathrm{C}$ during tensile test at a lower strain rate [151], and also after cold-drawing, cold-rolling, machining, or severe plastic deformation (e.g., [180]). $\alpha$-martensite can form through at least three mechanisms described hereafter.

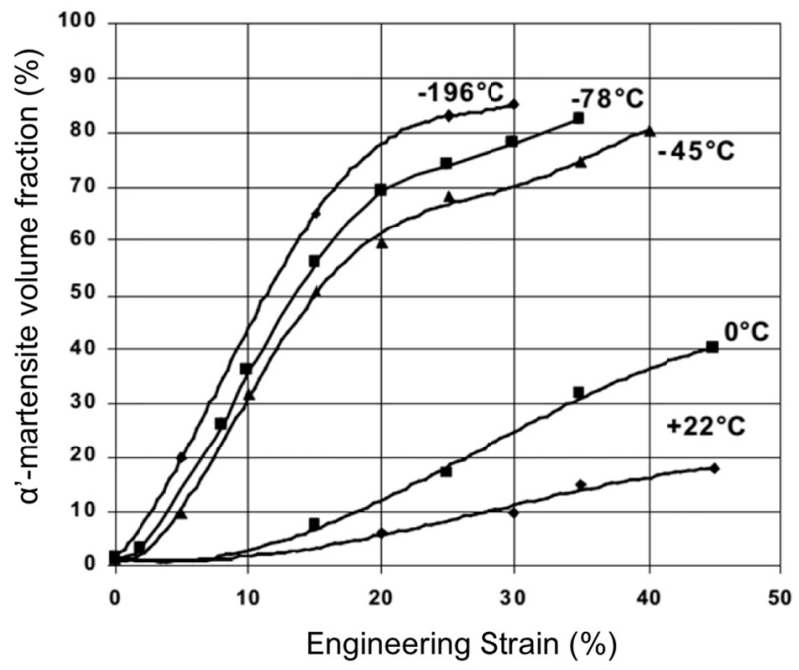

Fig. 27. Kinetic of formation of $\alpha^{\prime}$-martensite experimentally measured in 304 steel during tensile tests at different temperatures [179].

Stress-assisted $\gamma(\mathrm{fcc}) \rightarrow \alpha^{\prime}(\mathrm{bcc})$ leads to $\alpha^{\prime}$-martensite that is similar to the thermal $\alpha^{\prime}$-martensite forming spontaneously during cooling below $\mathrm{M}_{\mathrm{s}}$, with similar nucleation sites, and similar nucleation and growth processes. The interaction between the applied stress and the transformation strain effectively lowers the chemical driving force required for transformation [181]. This type of martensite consists in platelets having irregular shapes. The stress required for initiating the transformation increases with temperatures, because of the concomitant decrease of the chemical driving force. Consequently, the formation of stress-assisted $\alpha^{\prime}$-martensite becomes more difficult with increasing temperature, and appears at larger strains when flow stress has risen due to work hardening. The nucleation process is still unclear. Olson and Cohen [175] estimated that a critical stable $\alpha$ '-martensite nucleus requires a stack of roughly three or four Shockley partials on every third $\{111\}$ plane in Fe$30 \mathrm{Ni}$ alloy. Bogers and Burgers [182] proposed a mechanism based on the spreading of $1 / 6<112>$ Shockley partials onto three $1 / 18<112>$ transformation dislocations on successive $\{111\}$ plans. Some authors have evidenced the role of such transformation dislocations (e.g., [183]).

Strain-induced $\gamma(\mathrm{fcc}) \rightarrow \alpha^{\prime}(\mathrm{bcc})$ forms directly due to plastic strain and has characteristics (morphology, nucleation process, and other) different from thermal martensite. It leads to lath-shaped martensite nucleating on specific deformation-induced sites, mainly on shear bands (localized bands comprising slip bands, overlapping ESF, twins, and $\varepsilon$-martensite platelets) intersections (e.g., $[152,164,175,178,184])$. When the shear bands contain $\varepsilon$-martensite, the transformation is often designated as $\gamma(\mathrm{fcc}) \rightarrow \varepsilon(\mathrm{hcp}) \rightarrow \alpha^{\prime}(\mathrm{bcc})$. Pre-straining above $\mathrm{M}_{\mathrm{d}}$ increases the number of nucleation sites and significantly raises transformation rate during tensile tests below $\mathrm{M}_{\mathrm{d}}$ [164].

Several mechanisms have been proposed to describe the formation of strain-induced martensite. For instance, at the intersection of a (111) deformation twin and a (111) slip plane [7], a Shockley partial having a $1 / 6[1 \overline{2} \overline{1}]$ Burgers vector and gliding on the $(\overline{111})$ plane can split into two partials in the twinned region, $\frac{1}{6}[\overline{2} 1 \overline{1}]_{\text {twin }}$ and $\frac{1}{18}[\overline{1} \overline{1} 2]_{\text {twin }}$. The dislocation with Burgers vector $\frac{1}{18}[\overline{1} \overline{1} 2]_{\text {twin }}$, by moving along the interface, creates a small nucleus of $\alpha$ '-martensite. Similarly, based on the Bogers and Burgers' mechanism, Olson and Cohen proposed of model for $\alpha$ ' formation at the intersection of 
two bands of $\varepsilon$-martensite [185]. Recent high-resolution TEM observations have validated this model $[186,187]$.

Olson and Cohen [175] estimated that in austenitic stainless steel, each intersecting shear band must have a minimum thickness of about $27\{111\}$ planes (5 to $7 \mathrm{~nm}$ wide) to lead to a stable nucleus of $\alpha^{\prime}$-martensite, which was experimentally verified in [177]. The critical nucleus size is a function of the chemical free energy difference between the parent and $\alpha$ '-martensite phases. Thus, if the transformation occurs in $\varepsilon$-martensite, the chemical free-energy difference to be considered is the one between $\varepsilon$ - and $\alpha^{\prime}$-martensite. This difference is not as dependent on temperature or chemical composition as the one between $\gamma$ and $\alpha^{\prime}$-martensite phases [40].

Volume fraction of strain-induced $\alpha^{\prime}$-martensite increases by repeat apparition of nucleus, whose growth stops when they get in contact with one another. It results in a structure made up of irregular 'blocks" of $\alpha$ '-martensite (e.g., [177]). This block-type morphology produces a distinctly different appearance from $\alpha$ '-martensite morphologies characteristic of spontaneous (thermal) or stress-assisted martensite (platelets). Some models have been put forward to predict the quantity of strain-induced martensite from tensile strain (e.g., $[188,164])$.

$\gamma(\mathrm{fcc}) \rightarrow \varepsilon(\mathrm{hcp}) \rightarrow \alpha^{\prime}(\mathrm{bcc})$ has been observed through images such as shown in Fig. 28 during deformation at locations that are not the intersections of $\varepsilon$-martensite bands, e.g., [178,189,190,191]. It has been designated as stress-assisted in [178], although the mechanism that controls it has not been clarified yet. The transformation $\varepsilon(\mathrm{hcp}) \rightarrow \alpha^{\prime}(\mathrm{bcc})$ is likely easier that $\gamma(\mathrm{fcc}) \rightarrow \alpha^{\prime}(\mathrm{bcc})$, which agrees with observations in an austenitic stainless steel [189] where generation of $\varepsilon(\mathrm{hcp})$ during cryogenic pre-straining leads to forming $\alpha^{\prime}$-martensite at room temperature, while the as-received steel would not form it. Some crystallographic operations and mechanisms have been proposed in $[192,193]$.

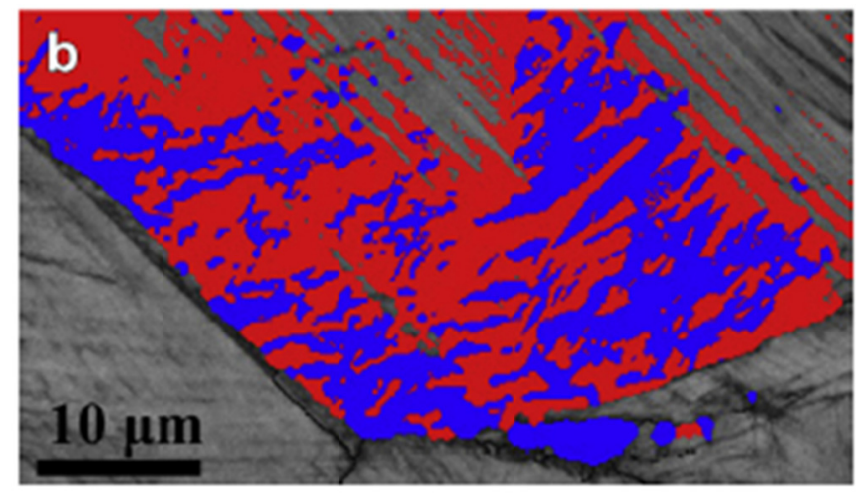

Fig. 28. $\alpha$ '-martensite (blue) formed in $\varepsilon$-martensite (red) in a Fe-18\%Mn-3\%Si-3\%Al-0.15\% $\mathrm{C}$ steel strained at room temperature at high strain rate $\left(>2.5 \times 10^{3} \mathrm{~s}^{-1}\right)[190]$.

\subsection{Transition between twinning, $\varepsilon$-martensite transformation, and slip}

\subsubsection{Effect of SFE}

Many authors, e.g., [28], have observed that the predominance of twinning, $\varepsilon$-martensite transformation, or slip in deformation of fcc materials is significantly dictated by the SFE (thus by temperature and composition). For austenitic steels, several authors $[11,40,61,194,195]$ reported the following approximate SFE domains:

- $\mathrm{SFE}>50 \mathrm{~mJ} / \mathrm{m}^{2}$ - plasticity dominated by slip,

- $15-18 \mathrm{~mJ} / \mathrm{m}^{2}<\mathrm{SFE}<50 \mathrm{~mJ} / \mathrm{m}^{2}$ - plasticity dominated by twinning and slip,

- $\mathrm{SFE}<15-18 \mathrm{~mJ} / \mathrm{m}^{2}$ - plasticity dominated by $\varepsilon$-martensite and slip. Remy has found similar orders of magnitude for Co-Ni alloys: SFE $<13-19 \mathrm{~mJ} / \mathrm{m}^{2}$ ( $\varepsilon$-martensite and slip), $15 \mathrm{~mJ} / \mathrm{m}^{2}<\mathrm{SFE}<60 \mathrm{~mJ} / \mathrm{m}^{2}$ (twinning and slip) [28]. In Fe-16\%Cr-13\% Ni, a similar value for the transition from $\varepsilon$-martensite to twin was observed $\left(20 \mathrm{~mJ} / \mathrm{m}^{2}\right)$, but twinning was not observed for SFE above $33 \mathrm{~mJ} / \mathrm{m}^{2}$ [22]. 
The SFE dependence of the type of plastic deformation can be explained as follows. At SFE $>50$ $\mathrm{mJ} / \mathrm{m}^{2}$, it is difficult for dislocations to dissociate into Shockley partials, and slip of perfect dislocations is favored, with easy cross-slip. For $15-18 \mathrm{~mJ} / \mathrm{m}^{2}<\mathrm{SFE}<50 \mathrm{~mJ} / \mathrm{m}^{2}$, perfect dislocation can dissociate more easily, which eases twin nucleation and growth, as aforementioned. Moreover, easier dissociation entails more difficult cross-slip, leading to longer dislocation pile-ups against obstacles - this very likely plays a key role in reaching the critical stresses for twin nucleation. At SFE $<15-18 \mathrm{~mJ} / \mathrm{m}^{2}$, the material transitions from a twinning- to an $\varepsilon$-martensite-based plasticity, as seen in Talonen and Hänninen's analysis [40]. The contraction associated with the fcc $\rightarrow$ hcp transformation can also play a role in favoring $\varepsilon$-martensite rather than twin nucleation, as analytically derived by Lecroisey and Pineau [7]. In practice, the transition from twinning- to $\varepsilon$-martensite-based plasticity is continuous, with coexistence of twins and $\varepsilon$-martensite of similar morphology over a small temperature range [28], as observed in Fig. 29. Allain [11] explains this transition as follows: in the twinning domain, Shockley partial dislocations are emitted on every $\{111\}$ plane, nucleating twins. As the SFE decreases the probability to miss the emission of a partial dislocation on one plane increases because the associated energy cost decreases, which nucleates faulted twins. The multiplication of such faulted twins leads to their ordering for energetic reasons, which leads to the formation of $\varepsilon$ martensite (see Fig. 30). Experimental observations from Fujita and Ueda [9] tend to confirm this model: they observed that at the beginning of formation of $\varepsilon$-martensite plates, the spacing between overlapping faults is random, then stacking of overlapping faults is progressively arranged on every second $\{111\}$ plane.

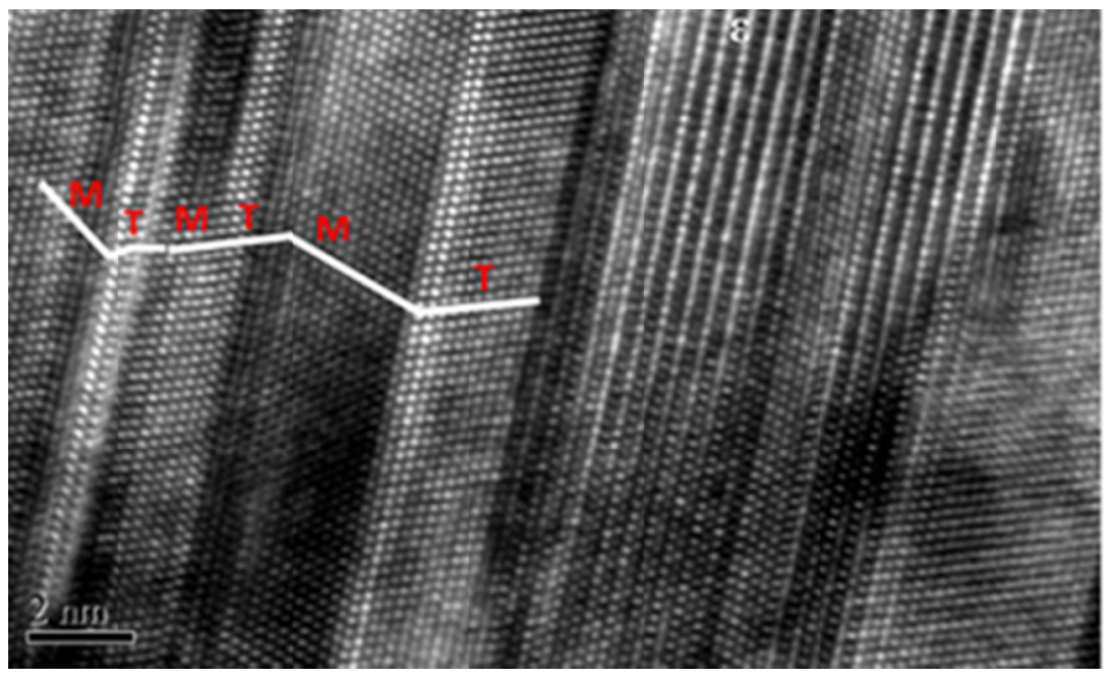

Fig. 29. High-Resolution TEM micrograph showing twins (T) and $\varepsilon$-martensite bands (M) in 304 steel after $57 \%$ tensile strain at room temperature, and strain rate of $10^{-3} \mathrm{~s}^{-1}$, from [89].
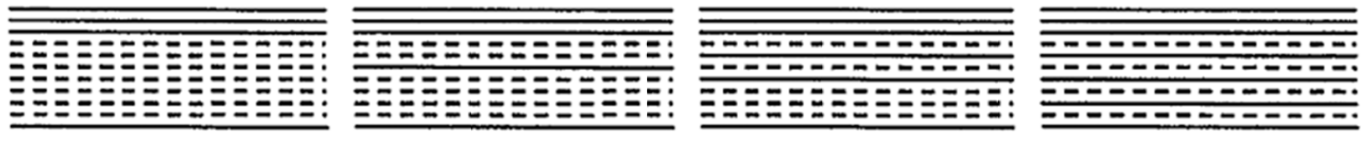

Fig. 30. Sketch showing the continuous transition from twinning to $\varepsilon$-martensite, from [11].

Although an appropriate SFE $\left(<50 \mathrm{~mJ} / \mathrm{m}^{2}\right)$ is likely a necessary condition for twinning or $\varepsilon$ martensite formation in austenitic steels, it seems that it is not a sufficient condition. One study on FeMn alloys [196] with similar SFE and different carbon contents observed that the carbon-free alloy did not twin, while alloys with $0.6 \mathrm{wt} \%$ of $\mathrm{C}$ twinned. Several explanations of this carbon effect have been reviewed by Allain [197]: carbon atoms can induce 1) a differential of DSA between leading and 
trailing Shockley partials that favors the widening of the stacking fault [111], 2) an impeding of the gliding of perfect dislocation, twinning becoming an alternative to satisfy the imposed strain [196], 3) a more planar plasticity (e.g., due to short-range order or increase in friction stress) favoring dislocation pile-ups and thus stress concentrations needed for twin nucleation [198], 4) an accumulation of mobile dislocations in certain zones due to DSA [199], favoring stress concentrations needed for twin nucleation. A sensitivity of deformation mechanism to carbon content was also reported in FeNiC alloys [200].

\subsubsection{Effect of strain rate}

In tensile test, for strain rates $<10^{-2} \mathrm{~s}^{-1}$, an increase in strain rate generally raises the flow stress in the material at a given strain [201] (outside the DSA domain), which should favor twinning and formation of $\varepsilon$-martensite, since critical nucleation stresses can be reached at smaller strain. Similarly, it favors the formation of deformation-induced $\alpha^{\prime}$-martensite by increasing the stress and the number of nucleation sites [184]. In the dynamic strain rate range $\left(>10^{-2} \mathrm{~s}^{-1}\right)$, these strain rate effects compete with an opposite effect. Higher strain rates create adiabatic conditions, in which the heat of plastic deformation is not dissipated fast enough. The corresponding specimen temperature rise can be estimated by computing the mechanical energy transferred to the specimen (i.e., the area under the stress-strain curve) and considering that a certain percentage of it (in general 90-95\%) is converted to thermal energy available to heat the specimen, e.g., $[202,203]$. This model was validated experimentally, for instance on 304 steel, where at $0.125 \mathrm{~s}^{-1}$ temperature increased from $24^{\circ} \mathrm{C}$ to $83^{\circ} \mathrm{C}$ by test end [204]. Higher temperature causes a) thermal softening, which leads to lower stress concentrations, b) a rise in SFE - which leads to easier cross-slip and less dissociation, and c) a decrease in the chemical driving force for $\alpha$ '- and $\varepsilon$-martensite. Several studies seem to confirm that $\alpha^{\prime}$-martensite formation is inhibited at strain rates $>10^{-2} \mathrm{~s}^{-1}$, e.g., $[153,204]$, but the effect on twinning and $\varepsilon$-martensite is less clear $[205,206]$.

\section{Effect of neutron irradiation}

\subsection{Irradiation-induced damage}

In steels under neutron irradiation, neutrons may collide with lattice atoms with two direct consequences: i) production of displacement cascades that may leave some non-recombined vacancies and self-interstitial atoms (SIA) after collapsing. These point defects may be isolated or gathered in very small clusters - ii) chemical or isotopic conversion of atoms via transmutation, which leads in particular to the production of helium and hydrogen gas. Those primary events are at the origin of damage within grains and at grain boundaries that may strongly affect steel plasticity. In the absence of significant formation of cavities (i.e., voids and gas bubbles), this damage reaches a dynamic equilibrium state after a dose of a few displacements per atom (dpa).

A huge body of literature has been devoted to neutron-induced damage and its effect on plasticity of 300 series steels, mainly in 316(L) and 304(L). Syntheses on both topics can be found for instance in $[1,90,207,208,209,210,211,212,213,214,215,216,217]$. They reveal in particular that the irradiation temperature and the neutron spectrum (i.e., neutron energy and flux) are very influent parameters. Thus, the present section focuses as much as possible on results obtained on 304(L) and 316(L) steels irradiated in LWR conditions (e.g., [218,219]) or, at least, at temperature below $400^{\circ} \mathrm{C}$. We will not distinguish cold-worked and annealed steels, since both types reach about the same dynamic equilibrium damage state (e.g., [220]) - a few more dpa are needed to reach this state for cold-worked steels because pre-introduced dislocations absorb part of the irradiation-induced point defects. Through a climb process, most of those dislocations have disappeared when the dose reaches a few dpa.

Residual point defects left by displacement cascades may migrate and form different types of clusters within grains. In $304(\mathrm{~L})$ and $316(\mathrm{~L})$ irradiated below $400^{\circ} \mathrm{C}$, Frank loops (faulted loops lying in $\{111\}$ planes, with a Burgers vector $1 / 3<111>$ ), stacking fault tetrahedra (SFT) and black dots are mainly reported (see in Fig. 31). Black dots are small defects $(\varnothing<5 \mathrm{~nm})$ that are difficult to 
characterize by conventional TEM studies, hence their name. Several authors postulated that black dots nucleate directly from cascade collapse (small point defect clusters).

For a long time, it was supposed that Frank loops were SIA-based and black dots were vacancybased. Recently, Edwards et al [207] put forward a new description of the damage based on experiments and a literature survey (e.g., [211,212,213,214]), according to which black dots are vacancy- and SIA-faulted Frank dislocation loops at irradiation temperature below about $300^{\circ} \mathrm{C}$. As the dose increases, vacancy loops do not grow whereas some SIA loops grow, which leads to loops (diameter $\approx 40 \mathrm{~nm}$ ) that are easily discernible by TEM. The stabilized density of black dots is 2 to $4 \times 10^{23} \mathrm{~m}^{-3}$ and the one for discernible Frank loops is about $1 \times 10^{23} \mathrm{~m}^{-3}$. At irradiation temperature above about $300^{\circ} \mathrm{C}$, black dots are only SIA loops because vacancy clusters are unstable and release vacancies in the matrix. The free vacancies allow the formation of gas-stabilized bubbles. As irradiation temperature increases (above $300^{\circ} \mathrm{C}$ ), SIA loops become larger (about $200 \mathrm{~nm}$ at $360^{\circ} \mathrm{C}$ ) to the detriment of the density of black dots, and are eventually transformed into dislocation lines after unfaulting (i.e., transformation into a perfect loops with a Burger vector of $1 / 2<110>$ ). Around $400^{\circ} \mathrm{C}$, large loops and dislocation lines become then the dominant stabilized damage within the grains.
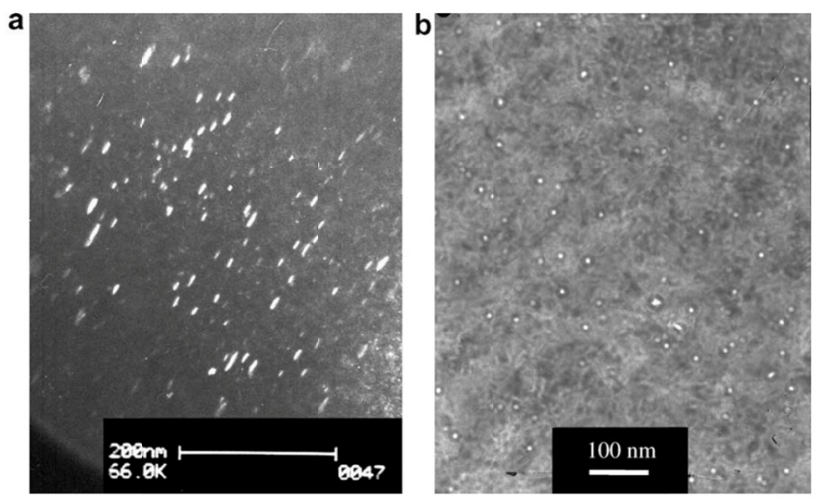

Fig. 31. Frank loops (a) and cavities (b) observed by TEM in a cold-worked 316L bolt neutron irradiated at about $365^{\circ} \mathrm{C}$ with a dose of about $13 \mathrm{dpa}$ in Tihange 1 plant [218].

At temperature below $400^{\circ} \mathrm{C}$, presence of SFT is often reported [221] but they constitute a very small part of the point defects clusters (less than $1 \%$ of visible defect population according to $[211,212])$. It should be mentioned that while both SIA- and vacancy-SFT can theoretically be expected, only the latter have been observed [207].

Vacancies can also accumulate in the shape of 3D voids, which may lead to swelling. The phenomenon plays a key role at irradiation temperature above $400^{\circ} \mathrm{C}$ and is not expected to occur below about $330^{\circ} \mathrm{C}$ for stainless steels. This means that in some thick parts or weakly cooled locations of internal structures of LWR, where temperature may go up to about $370^{\circ} \mathrm{C}$ due to $\gamma$ heating, formation of small voids and consequential swelling could happen. TEM observations revealed the presence of small cavities in $316 \mathrm{~L}$ bolts extracted from Tihange 1 plant (PWR) - for doses/irradiation temperatures of about $19.5 \mathrm{dpa} / 320^{\circ} \mathrm{C}$ and $12 \mathrm{dpa} / 360^{\circ} \mathrm{C}$, cavity densities were less than $10^{20}(\varnothing<2$ $\mathrm{nm})$ [219] and about $2.310^{21} \mathrm{~m}^{-3}(\varnothing=10 \mathrm{~nm})$ [218], respectively. At $360^{\circ} \mathrm{C}$, the cavities were interpreted as being gas bubbles and voids. It is known that 304(L) steel is less resistant than 316(L) steel to the onset of formation of cavities at irradiation temperature above $400^{\circ} \mathrm{C}$ [210]. If this result is still valid below $400^{\circ} \mathrm{C}$, small voids can also be expected in components in $304(\mathrm{~L})$ irradiated at temperature above about $330^{\circ} \mathrm{C}$ in LWR. TEM observations on a 304 steel irradiated in Chooz A plant (PWR) confirmed the absence of any voids after irradiation at about $300^{\circ} \mathrm{C}$ with a dose of $24 \mathrm{dpa}$ [222]. According to Garner [210], rapid formation and growth of voids require a significant density of mobile dislocations to quickly transport mass. The unfaulting of SIA-loops forms those mobile dislocations. Several modeling efforts are in progress to predict swelling in stainless steels irradiated in LWR conditions (e.g., [223]). 
As aforementioned, transmutation produces helium and hydrogen gas in irradiated stainless steels. Measurement of gas contents in the head of a 316L bolt extracted from Tihange 1 plant revealed i) a He production rate of about $6 \mathrm{ppm} / \mathrm{dpa}$ and ii) that the hydrogen produced by transmutation is negligible compared to the hydrogen that diffuses into the steel from the coolant [219]. At temperatures below $300^{\circ} \mathrm{C}$, gas seem to remain in solution or in small bubbles that are hardly observable by TEM $[211,212]$. A temperature higher than $300^{\circ} \mathrm{C}$, He bubbles are observed. The retention of hydrogen is not yet fully understood, but it might be partly stored in the solution, in $\mathrm{He}$ cavities, or in voids [219]. Formation of bubble contributes slightly to steel swelling and eases the formation of voids [210].

In LWR conditions, neutron irradiation also induces radiation-induced segregation (RIS), which leads to enrichment or depletion in certain elements in the vicinity of point defect sinks. In particular, RIS induces $\mathrm{Cr}$ and $\mathrm{Fe}$ depletion and $\mathrm{Ni}$ and $\mathrm{Si}$ enrichment within a zone having a width of about 10 $\mathrm{nm}$ along grain boundaries ( $5 \mathrm{~nm}$ on each side of the boundary). For instance, $\mathrm{C}_{\mathrm{Cr}} \approx 11 \mathrm{wt} \%, \mathrm{C}_{\mathrm{Fe}} \approx 57$ $\mathrm{wt} \%, \mathrm{C}_{\mathrm{Ni}} \approx 30 \mathrm{wt} \%$ and $\mathrm{C}_{\mathrm{Si}} \approx 4.5 \mathrm{wt} \%$ were measured in a grain boundary of a $316 \mathrm{~L}$ Tihange bolt after a dose of $12.2 \mathrm{dpa}$ at about $340^{\circ} \mathrm{C}$ [219]). Several mechanisms can explain RIS, in particular the Kirkendall effect or the drag of atoms by SIA (e.g., Si) and vacancies towards sinks (e.g., [224]).

RIS may also affect Frank loops as suggested by TEM [207, 222] and atom probe experiments [218]. Atom probe revealed small clusters with $\mathrm{Ni}$ and $\mathrm{Si}$ contents of about 50 and $40 \mathrm{at} \%$, and a concomitant depletion in $\mathrm{Fe}$ and $\mathrm{Cr}$ in a Tihange 316L bolt irradiated with a dose of $12 \mathrm{dpa}$ at about $360^{\circ} \mathrm{C}$. Segregation of $\mathrm{P}$ and Mo were also observed at the matrix/cluster interface. Those cluster have been interpreted as resulting from RIS [225]. Local enrichments are thought to increase the effective strength of the Franck loops as obstacles to dislocation glide. Thus, this strength may be strongly linked to the Si content, and be dose dependent [207]. To the authors' knowledge, the impact of RIS on loop unfaulting has not been characterized.

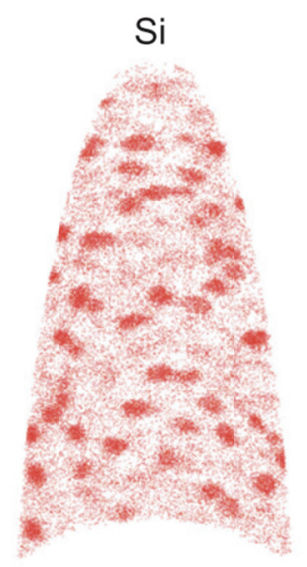

Fig. 32. Si-Ni rich zones observed by Atom Probe in a solution annealed 304 plate irradiated at about $300^{\circ} \mathrm{C}$ with a dose of about $24 \mathrm{dpa}[226]$.

Under irradiation, phases that are not predicted by equilibrium diagrams or that have altered chemical composition with respect to those diagrams may precipitate, and are named radiationinduced or radiation-modified phases (e.g., [210]). To the author's knowledge, in 316(L) and 304(L) irradiated in LWR conditions, only one irradiated-induced phase has been reported: $\gamma^{\prime}$ (type $\mathrm{Ni}_{3} \mathrm{Si}$ ) (e.g., [226]). Number densities of $0.6 \times 10^{23} \mathrm{~m}^{-3}(\varnothing \approx 3 \mathrm{~nm})$ and $4 \times 10^{23} \mathrm{~m}^{-3}(\varnothing \approx 10 \mathrm{~nm})$ were reported in a Tihange 316 bolt irradiated with a dose of 12.2 dpa at about $340^{\circ} \mathrm{C}$ [219], and in a Chooz A 304 plate irradiated with a dose of $24 \mathrm{dpa}$ at about $300^{\circ} \mathrm{C}$ (see in Fig. 32) [226], respectively. It is worth mentioning that it is rather difficult to distinguish $\gamma^{\prime}$ precipitates from RIS-induced Ni-Si clusters around SIA loops. This could explain some discrepancy in number densities or identification of the defects. Furthermore, it is not clear whether the two phenomena are distinct or if precipitation starts from the Ni-Si clusters. Observations carried out after irradiations in Fast Breeder Reactors at temperature below $400^{\circ} \mathrm{C}$ also revealed irradiation-induced precipitation of $\mathrm{G}$ Phase and $\mathrm{M}_{23} \mathrm{C}_{6}$ (e.g., 
[215]). Some modeling efforts are in progress in order to provide a full picture of the irradiationinduced microstructural evolution of stainless steels in LWR conditions (e.g., [215]).

\subsection{Irradiation-induced evolution of tensile properties}

The evolution of the tensile properties of 304 and 316 steels after irradiation below $400^{\circ} \mathrm{C}$ is illustrated in Fig. 33. It can be noticed that yield stress and ultimate strength increase with irradiation and reach a plateau after a few dpa. Concomitantly, uniform and total elongations decrease and reach a plateau for which the total and uniform elongations are about $10 \%$ and less than $1 \%$, respectively. On the plateau, necking, also named plastic instability, occurs shortly after yielding. Those plateaus occur because of the onset of a stabilized microstructure. Many modeling efforts have been carried out to forecast the evolution of tensile properties of stainless steels versus irradiation dose and temperature (e.g., [227,215]).

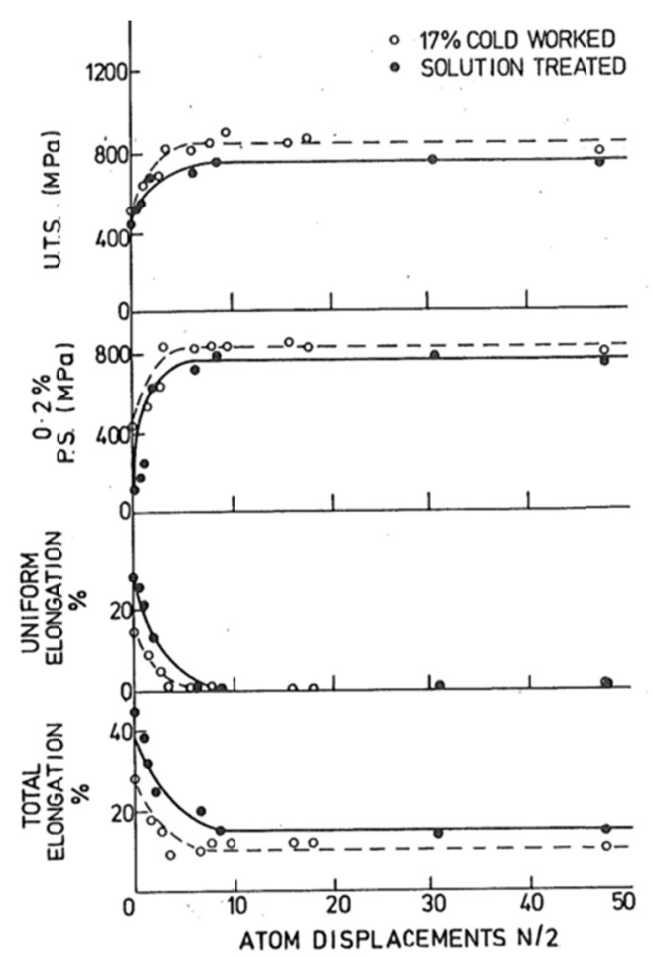

Fig. 33. Evolution with irradiation of the tensile properties of annealed and $17 \%$ cold-worked 316 stainless steels (test temperature $\approx$ irradiation temperature $\approx 300^{\circ} \mathrm{C}$ ) [228].

\subsection{Mechanisms controlling plasticity after irradiation}

Interactions between mobile dislocations and irradiation-induced point defect clusters (loops, SFT, voids) have been the subject of many studies, at first through phenomenological and analytical models (e.g., $[229,230,231,232])$, then trough molecular dynamics and dislocation dynamics simulation. In fcc materials, molecular dynamics (e.g., [233,234,235,236,237]) showed that dislocation loops and SFT may be either unaffected, sheared, partially absorbed, or totally absorbed by moving dislocations. Dislocations can shear gas bubbles and voids, which has been confirmed by TEM observations [238]. To the authors' knowledge, the mechanism that controls the passing of Ni-Si rich clusters/precipitates by dislocation has not yet been characterized.

Because of the number densities of irradiation-induced defects (as given in Paragraph 3.1), it is very likely that the evolution of tensile properties of 304(L) and 316(L) steels irradiated in LWR conditions be mainly controlled by vacancy- and SIA-Frank loops (according to Edward et al.'s black 
dots description [207]) and Ni-Si rich clusters (being $\gamma^{\prime}$ precipitates or clusters around Frank loops). Number densities of other irradiation-induced defects (SFT, voids, bubbles) are likely too low to have any significant effect.

It has be shown that i) the plasticity mechanisms described in Section 2 for tensile tests on unirradiated stainless steels are still operating after irradiation (except for maybe dynamic strain aging) and ii) their occurrence is also strongly dependent on temperature and strain rate, as well as on irradiation dose and temperature [90,239].

Shearing and absorption of defects by gliding dislocations lead to the formation of deformation bands free of point defect clusters, called clear bands or dislocation channels, in which most of the dislocation gliding is localized [240]. Through these processes, a first moving dislocation suppresses the defects or weakens their obstacle strength, and subsequent dislocations tend to follow the same path. Dislocation dynamics simulations [241] showed that i) formation of helical turns on screw dislocations and double cross-slip play a key role in the formation and thickening of clear bands, and ii) this formation requires dislocation pile-ups to get to a stress concentration that is high enough to unpin the first dislocations that initiate the clear band. EBSD studies showed that high local strain fields are produced at the intersection of grain boundaries and clear bands [242]. Formation and evolution of clear bands, their interactions with other microstructural features such as grain boundaries, and their dependence on grain orientation are still active research topics.

The interplay between radiation damage, clear bands, twinning, and martensite formation is still unclear. Some radiation-induced defects might act as nucleation sites for twins and martensite laths as suggested in [239] for 316 steel and in [243] for 304L steel. To the authors' knowledge, the role played by RIS on the SFE along grain boundaries, and then on the nucleation of twins or martensite laths from those boundaries, has not yet been studied.

Based on experimental observations and phenomenological approaches, Byun et al. [90] proposed a deformation mode map of irradiated 316 stainless steels in true stress-dose space for tensile tests at room temperature (Fig. 34). According to this map, the true stress for formation of extended stacking fault, twinning, and plastic instability (necking) are dose independent, and thus can be measured at the unirradiated state. At a dose of a few dpa, the yield stress reaches the necking stress (PIS: Plastic Instability Stress) and uniform elongation is quasi-null.

Some results on the effect of tensile test temperature on the occurrence of the plasticity mechanisms after irradiation are also available [239]. Unlike for unirradiated stainless steels, formation of twins and martensite laths has been reported for tensile tests carried out at temperature higher than $300^{\circ} \mathrm{C}$ after irradiation.

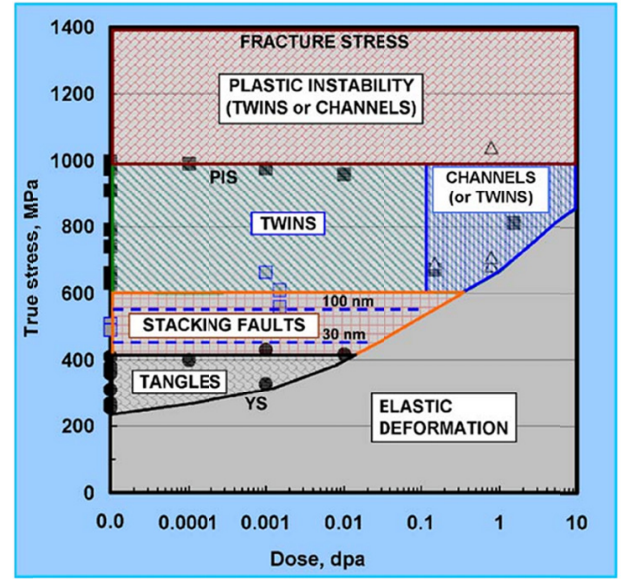

Fig. 34. Deformation mode map for 316 and 316LN stainless steels in the true stress-dose space, from [90]. PIS: Plastic Instability Stress (onset of necking).

\section{Grain rotation}

To the authors' knowledge, no data on grain rotation in irradiated fcc materials is available, thus this section will focus on unirradiated materials. In a polycrystal under uniaxial tension, grains rotate 
to accommodate their deformation and that of other grains. This behavior has been extensively studied based on two historical models proposed by Sachs [244] and Taylor [245], and their derived forms. As shown for copper in Fig. 35, these two models are often considered as the lower- and upper-bound theories of polycrystal plasticity, respectively. In Sachs' model, it is considered that the stress in each grain is the applied stress and the deformation relies on the most loaded slip system (highest Schmid factor). In practice, such a condition should prevent grains from remaining in contact. In Taylor's model, strain is the same in each grain and equals the macroscopic strain. To meet this condition, five shear systems have to be activated in each grain. In Taylor's original article, these shear systems are slip systems, but they could be also twin or $\varepsilon$-martensite formation systems. Taylor's model predicts than grains rotate in order to get the tensile axis along the $<110>-<111>$ side of the standard stereographic triangle.

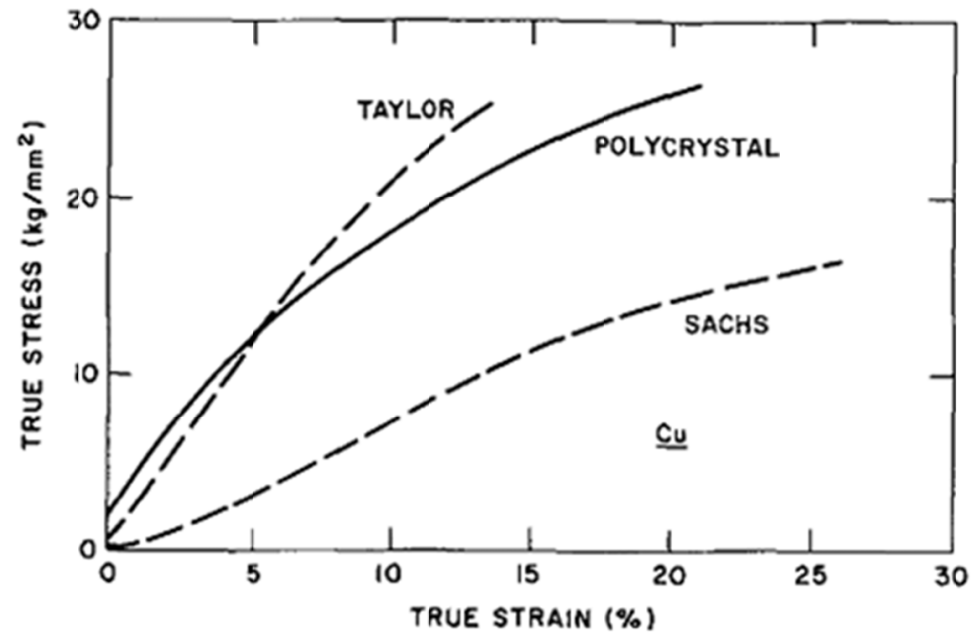

Fig. 35. Tensile stress-strain curve for a poly-crystal of copper at room temperature and comparison with theoretical curves based on the Sachs and Taylor models [246].

Several studies have been carried out on fcc single crystals to apprehend fundamentals of grain deformation according to their orientation with respect to the tensile axis (e.g., $[58,73,75,247,248,249,250])$ and better understand grain rotation during tensile test. Theoretical approaches showed that when a single crystal is deformed in tension along the ' $\mathrm{D}$ ' direction shown in Fig. 36a, slip occurs along the [101] direction upon the (111) plane of the crystal in the early stage of deformation [251]. As the deformation proceeds, the slip direction [101] in the crystal rotates toward the tensile axis, thus the rotation may be represented as the movement of the tensile axis ' $\mathrm{D}$ ' toward the [1]01] direction. As a result this lattice rotation causes the tensile axis to rotate from ' $D$ ' to ' $O$ ', after which the crystal becomes oriented so that two slip systems have the same maximum Schmid factor, resulting in occurrence of duplex slip. Experimentally, it has been observed that single crystal rotation is strongly dependent on its initial orientation with respect to the tensile axis, e.g., [250].

Grain rotation during tensile tests of polycrystals has been experimentally studied with TEM [85], X-Ray Diffraction (XRD) (e.g., [252]) Electron Backscattered Diffraction (EBSD) technique (e.g., [74]), and neutron diffraction (e.g., [253]). TEM has a very high resolution, but gives only information on a limited area and requires a long sample preparation time. X-Rays generally have a low penetration depth unless they are synchrotron high-energy X-rays (50-100 keV), which can go as deep as $4 \mathrm{~cm}$ in light materials such as aluminum [254]. EBSD has become a very popular technique available in many labs since easy to implement, but it only provides information on surface grains. Neutrons penetrate 1,000 times deeper than X-rays in iron, and have been used in many studies to study grains in the bulk.

Grain rotation in fcc polycrystals with slip-based plasticity has been mainly studied in pure metals with high SFE (e.g., pure $\mathrm{Al}$ or $\mathrm{Cu}$ ) at room temperature. It was observed that strain-induced grain rotation (measured in the centered of grains) mainly depends on the initial grain orientation prior to deformation $[252,254,255,256,257]$. Most authors agreed on grain rotation paths similar to those 
sketched in Fig. 36b, which is in agreement with the analysis done by Taylor [245]: it appears that after significant strains of an initially random-textured fcc material, most of the grains have a $<111>$ close to the tensile axis, and a minority of grains turns out with a $<100>$ direction close to this axis. No grain is expected to have a $<110>$ direction close to the tensile axis. Some work has also been carried out to study grain rotation in fcc materials with plasticity relying on slip and twinning (e.g., $[122,141,142,258])$ or on slip and $\varepsilon$-martensite formation ([174,259] for $\varepsilon$-martensite). Results similar to those obtained for slip-based plasticity have been produced (see Fig. 19, for twinning and Fig. 26 for $\varepsilon$-martensite). The grains containing twins or $\varepsilon$-martensite are mostly those for which a $<111>$ direction is almost parallel to the tensile axis.

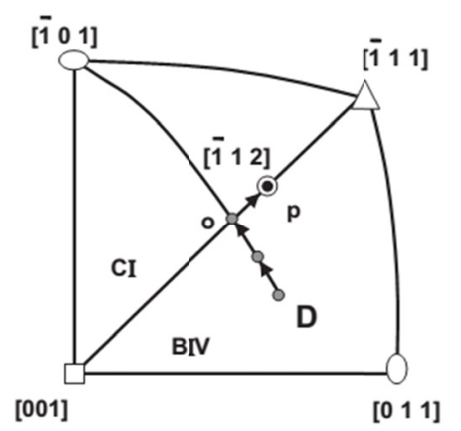

a) As theoretically predict for a single crystal.

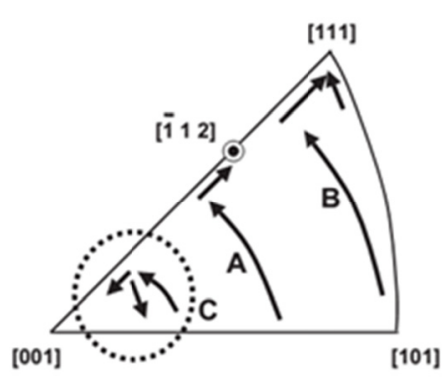

b) As measured in poly-crystalline sample.

Fig. 36. Grain rotation in fcc materials in which deformation occur by slip during uniaxial deformation (here pure aluminum). Arrows show the rotation path of the tensile axis in the standard stereographic triangle [255].

\section{Conclusion}

During tensile test below $400^{\circ} \mathrm{C}$, plasticity of annealed austenitic stainless steels is mainly controlled by five intragranular mechanisms which interact and compete with one another: i) slip, ii) dynamic strain aging, iii) formation of extended stacking faults, iv) twinning, v) $\alpha^{\prime}$ and $\varepsilon$-martensite formation. In addition, the mechanism of grain rotation has to be considered. These mechanisms are for the most part well understood and characterized, but there are some remaining gaps, including:

- the dependence of the stacking fault energy on composition is poorly known, in particular for 316 stainless steel,

- the nature of atoms, and their interactions with dislocations, that control dynamic strain aging are not fully known. Likewise, the transition between individual behavior and collective behavior (Portevin-Le Châtelier effect) of dislocations is not well understood,

- for certain alloys such as 304 and 316 stainless steels, it seems that the dynamic strain aging and twinning tend to exclude each other, i.e., twinning is suppressed when dynamic strain aging occurs, but the interplay between both mechanisms is not well understood.

Understanding of the effects of these plasticity mechanisms on the mechanical properties of austenitic steels made large progress during recent years, in particular thanks to efforts on TWIP and TRIP steels. However, there is still a lot to understand, for instance on the large temperature-induced decrease of ductility of 304(L) and 316(L) austenitic stainless steels between room temperature and about $300^{\circ} \mathrm{C}$, and the effects of plasticity mechanisms on their (irradiation-assisted) stress corrosion cracking behavior or fracture toughness.

The nature of irradiation-induced damage in austenitic stainless steels is now well understood. However, the interplay between this damage, clear bands, twinning, and martensite formation is still unclear. In particular, it is worth understanding why critical stresses for twinning, formation of extended stacking fault, and necking are dose-independent, while the microstructural evolution is not (at least up to a few dpa). It is also interesting to characterize grain rotation during tensile tests on irradiated steels. 
Occurrence of the aforementioned plasticity mechanisms is strongly dependent on chemical composition and experimental conditions like temperature, strain and strain rate. Slight modifications of these parameters may induce large differences in plasticity, obtained microstructure, and thus mechanical and corrosion properties. To the authors' knowledge, this high sensitivity is not currently taken into account by the nuclear industry. For instance, 304(L) and 316(L) stainless steels used in Light Water Reactors are ordered following ASTM chemical compositions or minimal mechanical properties, despite the large range of compositions allowed by many grades (e.g., $4 \mathrm{wt} \%$ for $\mathrm{Ni}$ in $304 \mathrm{~L}$ and $316 \mathrm{~L}$ ), or the various possible thermo-mechanical routes to achieve cold work. There is likely a large potential of improvement of austenitic stainless steel behaviors by tailoring their plasticity for nuclear applications, while staying within their grade specifications. This would lead, for instance, to tighten chemical specifications or precisely adjust cold work or machining conditions.

\section{Acknowledgments}

The authors would like to thank Dr. Kumar Sridharan for his review of the manuscript. This material is based upon work initially supported under the Jack and Marion Goetz Engineering Fellowship in the Department of Nuclear Engineering and Engineering Physics at University of Wisconsin Madison, and then under a DOE Integrated University Program Graduate Fellowship. 
[1] J.C. Van Duysen, P. Todeschini, G. Zacharie, Effects of neutron irradiations at temperatures below $500^{\circ} \mathrm{C}$ on the properties of cold worked 316 stainless steels: a review, in: A.S. Kumar, D.S. Gelles, R. Nanstad, E.A. Little (Eds.), Effects of Radiation on Materials: 16th International Symposium, ASTM STP 1175, American Society for Testing and Materials, Philadelphia, 1993.

[2] O. Raquet, E. Herms, F. Vaillant, T. Couvant, Adv. Mater. Sci. 1 (2007) 33.

[3] P. Scott, Materials reliability program: a review of the cooperative irradiation assisted stress corrosion cracking research program (MRP-98), in: EPRI 1002807, Palo Alto, CA, 2003.

[4] O.K. Chopra, A.S. Rao, J. Nucl. Mater. 409 (2011) 235.

[5] L. Tan, K. Sridharan, T.R. Allen, R.K. Nanstad, D. a. McClintock, J. Nucl. Mater. 374 (2008) 270.

[6] K.H. Lo, C.H. Shek, J.K.L. Lai, Mater. Sci. Eng. R Reports 65 (2009) 39.

[7] F. Lecroisey, A. Pineau, Metall. Trans. 3 (1972) 387.

[8] W. Karlsen, M. Ivanchenko, U. Ehrnstén, Y. Yagodzinskyy, H. Hänninen, J. Nucl. Mater. 395 (2009) 156.

[9] H. Fujita, S. Ueda, Acta Metall. 20 (1972) 759.

[10] T. S. Byun, N. Hashimoto, K. Farrell, Acta Mater. 52 (2004) 3889.

[11] S. Allain, Caractérisation et modélisation thermomécaniques multi-échelles des mécanismes de déformation et d'écrouissage d'aciers austénitiques à haute teneur en manganèseApplication à l'effet TWIP, Ph.D. thesis, Institut National Polytechnique de Lorraine, 2004.

[12] X. Wu, X. Pan, J. F. Stubbins, Embrittlement and Flow Localization of Reactor Structure Materials, 2006.

[13] M.N. Gussev, J.T. Busby, T.S. Byun, C.M. Parish, Mater. Sci. Eng. A 588 (2013) 299.

[14] Y. Lü, B. Hutchinson, D.A. Molodov, G. Gottstein, Acta Mater. 58 (2010) 3079.

[15] G. Kim, S. K. Kim, S. W. Hwang, C. S. Lee, K. T. Park, Proceedings Materials Sciences \& Technology 2009, October 25-29, 2009: Pittsburgh, PA.

[16] J.E. Jin, Y.K. Lee, Mater. Sci. Eng. A 527 (2009) 157.

[17] J.W. Morris Jr, J.W. Chan, Z. Mei, in:, Fourteenth Int. Cryog. Eng. Conf. Int. Cryog. Mater. Conf. Kiev, Ukr. June 8-I2, 19'92, 1992.

[18] T.J. Balk, K.J. Hemker, Philos. Mag. A 81 (2001) 1507.

[19] D. Hull, D. J. Bacon. Introduction to dislocations. Vol. 257. Oxford: Pergamon Press, 1984.

[20] T.S. Byun, Acta Mater. 51 (2003) 3063.

[21] J.B. Baudouin, G. Monnet, M. Perez, C. Domain, A. Nomoto, Mater. Lett. 97 (2013) 93.

[22] L. Rémy, A. Pineau, Mater. Sci. Eng. 36 (1978) 47.

[23] R.P. Reed, R.E. Schramm, J. Appl. Phys. 45 (1974) 4705.

[24] M. Kang, W. Woo, Y.-K. Lee, B.-S. Seong, Mater. Lett. 76 (2012) 93.

[25] R. E. Smallman, K. H. Westmacott, Philos. Mag. 2 (1957) 669.

[26] N.I. Noskova, V.A. Pavlov, Phys. Metals Metall. 14 (1962) 87.

[27] D. Rafaja, C. Krbetschek, C. Ullrich, S. Martin, J. Appl. Crystallogr. 47 (2014) 936.

[28] L. Rémy, Maclage et transformation martensitique CFC HC induite par déformation plastique dans les alliages austénitiques à basse énergie de défaut d'empilement des systèmes Co-Ni-Cr-Mo et Fe-Mn-Cr-C, PhD Thesis, Université Paris Sud, Paris, 1975.

[29] T. Yonezawa, K. Suzuki, S. Ooki, A. Hashimoto, Metall. Mater. Trans. A 44 (2013) 5884.

[30] R.E. Schramm, R.P. Reed, Metall. Trans. A 6 (1975) 1345.

[31] C.G. Rhodes, A.W. Thompson, Metall. Trans. A 8 (1977) 1901.

[32] F.B. Pickering, in:, Proc. Conf. Stainl. Steels 84, Gothenburg, 1984, 1984, pp. 2-28.

[33] P. J. Brofman G. S. Ansell, Metall. Trans. A, 9 (1978), p. 879.

[34] D. Qi-Xun, W. An-Dong, C. Xiao-Nong, L. Xin-Min Chinese Phys. 11 (2002) 596.

[35] M. Ojima, Y. Adachi, Y. Tomota, Y. Katada, Y. Kaneko, K. Kuroda, H. Saka, 80 (2009) 477.

[36] G. Meric de Bellefon, C. Domain, J. C. van Duysen, K. Sridharan, Proc. ICAPP, San Francisco, CA (2016).

[37] S.W. Yang, J.E. Spruiell, J. Mater. Sci. 17 (1982) 677. 
[38] Y. Petrov, Int. J. Mater. Res., 103, 551 (2012).

[39] P. Behjati, A. Najafizadeh, Metall. Mater. Trans. A 42 (2011) 3752.

[40] J. Talonen, H. Hänninen, Acta Mater. 55 (2007) 6108.

[41] J. F. A. Borges, A. F. Padilha, K. Imakuma. Determination of the stacking fault energies of face centured cubic metals and alloys by X-rays diffraction. Instituto de Pesquisas Energeticas e Nucleares, Sao Paulo, SP (Brazil), 1988.

[42] E. D. Butakova, K. A. Malyshev, N. I. Noskova., Fizika Metallov i Metallovedenie 35.3 (1973) 662.

[43] R. Fawley, R., M. A. Quader, R. A. Dodd. "Compositional effects on the deformation modes, annealing twin frequencies, and stacking fault energies of austenitic stainless steels." TRANS MET SOC AIME 242.5 (1968) 771.

[44] L.E. Murr, Thin Solid Films 4 (1969) 389.

[45] Z. Jiao, G. Was, J. Nucl. Mater. 407 (2010) 34.

[46] J.B. Vogt, J. Foct, C. Regnard, G. Robert, J. Dhers, Metall. Trans. A 22 (1991) 2385.

[47] R. Taillard, J. Foct, in:, J. Foct, A. Hendry (Eds.), High Nitrogen Steels, HNS 88, Inst. Met. London, 1989, p. 387.

[48] N. Luzginova, H. Sehitoglu, I. Karaman, 45 (2002) 274.

[49] J.M. Silcock, Corros. - NACE 38 (1982) 144.

[50] O. Bouaziz, S. Allain, C.P. Scott, P. Cugy, D. Barbier, Curr. Opin. Solid State Mater. Sci. 15 (2011) 141.

[51] S. Ogata, J. Li, S. Yip, Phys. Rev. B - Condens. Matter Mater. Phys. 71 (2005) 1.

[52] S. A. Kibey, L.L. Wang, J.B. Liu, H.T. Johnson, H. Sehitoglu, D.D. Johnson, Phys. Rev. B Condens. Matter Mater. Phys. 79 (2009) 1.

[53] S. Kibey, J.B. Liu, D.D. Johnson, H. Sehitoglu, Acta Mater. 55 (2007) 6843.

[54] S. Kibey, J.B. Liu, M.J. Curtis, D.D. Johnson, H. Sehitoglu, Acta Mater. 54 (2006) 2991.

[55] V. Vitek, Philos. Mag. 18 (1968) 773.

[56] J. R. Rice, J. Mech. Phys. Solids 40 (1992) 239.

[57] L. Vitos, J.O. Nilsson, B. Johansson, Acta Mater. 54 (2006) 3821.

[58] I. Karaman, H. Sehitoglu, H.J. Maier, Y.I. Chumlyakov, Acta Mater. 49 (2001) 3919.

[59] A. Dumay, J.P. Chateau, S. Allain, S. Migot, O. Bouaziz, Mater. Sci. Eng. A 483-484 (2008) 184.

[60] S. Curtze, V.T. Kuokkala, a. Oikari, J. Talonen, H. Hänninen, Acta Mater. 59 (2011) 1068.

[61] G.B. Olson, M. Cohen, Metall. Trans. A 7 (1976) 1897.

[62] A. Saeed-Akbari, J. Imlau, U. Prahl, W. Bleck, Metall. Mater. Trans. A Phys. Metall. Mater. Sci. 40 (2009) 3076.

[63] D.T. Pierce, J. a. Jiménez, J. Bentley, D. Raabe, C. Oskay, J.E. Wittig, Acta Mater. 68 (2014) 238.

[64] L. Vitos, P. a. Korzhavyi, B. Johansson, Phys. Rev. Lett. 96 (2006) 1.

[65] H. Gholizadeh, The Influence of Alloying and Temperature on the Stacking-Fault Energy of Iron-Based Alloys, 2013.

[66] L. A. A. Warnes, H.W. King, Cryogenics (Guildf). 16 (1976) 659.

[67] Hirth JP, Lothe J. Theory of dislocations. 2nd ed. New York (NY): Wiley Interscience; 1982.

[68] M.S. Duesbery, Model. Simul. Mater. Sci. Eng. 6 (1999) 35.

[69] E. Schmid, W. Boas., Kristallplastizität: mit besonderer Berücksichtigung der Metalle. 17. Springer-Verlag (2013)

[70] M. A. Tschopp, D.L. McDowell, Appl. Phys. Lett. 90 (2007) 1.

[71] I. Salehinia, D.F. Bahr, Int. J. Plast. 52 (2014) 133.

[72] R.W.K. Honeycombe, The Plastic Deformation of Metals, Edward Arnold Ltd., London, 1968.

[73] T. Takeuchi, Trans. Japan Inst. Met. 16 (1975) 629.

[74] P. Franciosi, A. Zaoui, Acta Mater. 30 (1982) 1627.

[75] U. Kocks, Acta Metall. 8 (1960) 345.

[76] W. Vorbrugg, H.C. Goetting, C. Schwink, Phys. Stat. Sol. 46 (1971) 257.

[77] B. Devincre, T. Hoc, L.P. Kubin, Mater. Sci. Eng. A 400-401 (2005) 182. 
[78] L. Kubin, Dislocations, mesoscale simulations and plastic flow. Vol. 5. Oxford University Press, 2013.

[79] Z.Q. Wang, I.J. Beyerlein, R. LeSar, Philos. Mag. 88 (2008) 1321.

[80] C. Déprés, C. F. Robertson, M. C. Fivel, Philos. Mag. 84 (2004) 2257

[81] A.M. Hussein, S.I. Rao, M.D. Uchic, D.M. Dimiduk, J.A. El-Awady, Acta Mater. 85 (2015) 180.

[82] J. D. Yoo, K. T. Park, Mater. Sci. Eng. A 496 (2008) 417.

[83] V. Gerold, H.P. Karnthaler, Acta Metall. 37 (1989) 2177.

[84] L. Kubin, B. Devincre, T. Hoc, Mater. Sci. Eng. A 483-484 (2008) 19.

[85] N. Hansen, X. Huang, Acta Mater. 46 (1998) 1827.

[86] N. Hansen, X. Huang, W. Pantleon, G. Winther, Philos. Mag. 86 (2006) 3981.

[87] N. Hansen, X. Huang, G. Winther, Metall. Mater. Trans. A 42 (2011) 613.

[88] F. Delaire, J.L. Raphanel, C. Rey, Acta Mater. 48 (2000) 1075.

[89] Y.F. Shen, X.X. Li, X. Sun, Y.D. Wang, L. Zuo, Mater. Sci. Eng. A 552 (2012) 514.

[90] T.S. Byun, N. Hashimoto, K. Farrell, J. Nucl. Mater. 351 (2006) 303.

[91] T.S. Byun, E.H. Lee, J.D. Hunn, J. Nucl. Mater. 321 (2003) 29.

[92] I. Karaman, H. Sehitoglu, K. Gall, Y.I. Chumlyakov, H.J. Maier, Acta Mater. 48 (2000) 1345.

[93] B. Jiang, T. Tadaki, H. Mori, T.Y. Hsu (Xu Zuyao), Mater. Trans. JIM 38 (1997) 1072.

[94] R. Tamhankar, J. Plateau, C. Crussard, Rev. Metall. 55 (1958) 383.

[95] S.-H. Cho, Y.-C. Yoo, J.J. Jonas, J. Mater. Sci. Lett. 19 (2000) 2019.

[96] U. Ehrnstén, A. Toivonen, Y. Yagozinskyy, H. Hänninen, Dynamic strain ageing of deformed nitrogen alloyed AISI 316 stainless steels, 2005.

[97] R. Picu, Acta Mater. 52 (2004) 3447.

[98] M. Ivanchenko, Dynamic strain Aging of Austenitic Stainless Steels and Ni-Base alloys, $\mathrm{PhD}$ thesis, Aalto University, Finland, 2010.

[99] A. H. Cottrell: A note on the Portevin-Le Châtelier effect. Philos. Mag. 44:829-832 (1953).

[100] P. McCormigk, Acta Metall. 20 (1972) 351.

[101] A. van den Beukel, Phys. Status Solidi 30 (1975) 197.

[102] L.H. De Almeida, I. Le May, P.R.O. Emygdio, Mater. Charact. 41 (1998) 137.

[103] W.S. Owen, M. Grujicic, Acta Mater. 47 (1999) 111.

[104] A. Yilmaz, Sci. Technol. Adv. Mater. 12 (2011) 063001.

[105] P. Hähner, Mater. Sci. Eng. A 207 (1996) 216.

[106] M.A. Lebyodkin, Y. Brechet, Y. Estrin, L.P. Kubin, Phys. Rev. Lett. 74 (1995) 4758.

[107] P. Hähner, E. Rizzi, Acta Mater. 51 (2003) 3385.

[108] M.A. Lebedkin, L.R. Dunin-Barkovskii, Phys. Solid State 40 (1998) 447.

[109] K. Peng, K. Qian, W. Chen, Mater. Sci. Eng. A 379 (2004) 372.

[110] S. L. Mannan, K. G. Samuel, P. Rodriguez, Trans. Ind. Inst. Metals 36 (1983) 313

[111] M. Koyama, T. Sawaguchi, T. Lee, C.S. Lee, K. Tsuzaki, Mater. Sci. Eng. A 528 (2011) 7310.

[112] Y. N. Dastur, W. C. Leslie, Metall. Trans. 12A (1981), p.749

[113] B. Hutchinson, N. Ridley, Scr. Mater. 55 (2006) 299.

[114] D.W. Kim, W. Ryu, J.H. Hong, S.-K. Choi, J. Mater. Sci. 33 (1998) 675.

[115] V. Ganesan, M. D. Mathew, K. B. Sankara Rao, , Mat. Sci. Technol. 25 (2009) 614.

[116] U. Ehrnstén, M. Ivanchenko, V. Nevdacha, Y. Yagodzinskyy, A. Toivonen, H. Hanninen, Proc. 12th Int. Conf. Environ. Degrad. Mater. Nucl. Power Syst. - Water React. (2005) 1475.

[117] S. G. Hong, S. B. Lee, J. Nucl. Mater. 328 (2004) 232.

[118] M. Ivanchenko, U. Ehrnstén, V. Nevadacha, Y. Yagodzinskyy, H. Hänninen, Proc. 7th Int. Conf. High Nitrogen Steels (2004) 641.

[119] J.W. Christian, S. Mahajan, Prog. Mater. Sci. 39 (1995) 1.

[120] M. Niewczas, "Dislocations and twinning in face centred cubic crystals", chap. 75 in "Dislocations in Solids", Edited by F. R. N. Nabarro, J. P. Hirth, Ed. Elsevier, (2007).

[121] L. Rémy, Acta Metall. 26 (1978) 443. 
[122] I. Gutierrez-Urrutia, S. Zaefferer, D. Raabe, Mater. Sci. Eng. A 527 (2010) 3552.

[123] M. A. Meyers, O. Vöhringer, V. a. Lubarda, Acta Mater. 49 (2001) 4025.

[124] V. Yamakov, D. Wolf, S.R. Phillpot, A.K. Mukherjee, H. Gleiter, Nat. Mater. 1 (2002) 45.

[125] J. Xu, W. Lin, A.J. Freeman, Phys. Rev. B 43 (1991) 2018.

[126] P. Haasen, A. King, Z. Metallkd. 51 (1960) 722.

[127] I. M. Robertson, Philos. Mag. A 54 (1986) 821.

[128] Pond RC, Garcia-Garcia LMF. Inst Phys Conf Ser 1981;61:495.

[129] W. Z. Han, G. M. Cheng, S. X. Li, S. D. Wu, Z. F. Zhang, Phys. Rev. Lett. 101 (2008) 3.

[130] M. Chen, E. Ma, K.J. Hemker, H. Sheng, Y. Wang, X. Cheng, Science (80-. ). 300 (2003) 1275.

[131] X. Wu, X. Pan, J.C. Mabon, M. Li, J.F. Stubbins, J. Nucl. Mater. 356 (2006) 70.

[132] R. W. Armstrong, P J. Worthington, in Metallurgical Effects at High Strain Rates, ed. R. W. Rohde, B. M. Butcher, J. R. Holland and C. H. Karnes. Plenum Press, New York, 1973, pp. 401-414.

[133] O. Vöhringer, Metall. 30 (1976) 1150.

[134] R. Ueji, N. Tsuchida, D. Terada, N. Tsuji, Y. Tanaka, A. Takemura, K. Kunishige, Scr. Mater. 59 (2008) 963.

[135] R.D.K. Misra, B.R. Kumar, M. Somani, P. Karjalainen, Scr. Mater. 59 (2008) 79.

[136] H. Idrissi, K. Renard, L. Ryelandt, D. Schryvers, P.J. Jacques, Acta Mater. 58 (2010) 2464.

[137] J. A. Venables, Deformation Twinning, Proceedings of a Metallurgical Society Conference, Gainesville, Floride, USA, (mars 1963), published by Gordon and Breach Science, NewYork, USA, (1964) p 77-116.

[138] S. Miura, J.-I. Takamura, N. Narita, Trans. JIM 9 (1968) 555.

[139] T. Mori and H. Fujita, Acta Metall. 28 (1980) 771.

[140] S. Mahajan, G.Y. Chin, Acta Metall. 21 (1973) 303.

[141] P. Yang, Q. Xie, L. Meng, H. Ding, Z. Tang, Scr. Mater. 55 (2006) 629.

[142] X.H. Fang, P. Yang, F.Y. Lu, L. Meng, J. Iron Steel Res. Int. 18 (2011) 46.

[143] L. Bracke, L. Kestens, J. Penning, Scr. Mater. 61 (2009) 220.

[144] Y. Chen, H. H. Ruan, J. Wang, H. L. Chan, Q. Wang, Q. Li, J. Lu, Acta Mater. 59 (2011) 3697.

[145] H.C. Choi, T.K. Ha, H.C. Shin, Y.W. Chang, Scr. Mater. 40 (1999) 1171.

[146] L. Remy, Metall. Trans. A 12A (1981) 387.

[147] B. Qin, H.K.D.H. Bhadeshia, Mater. Sci. Technol. 24 (2008) 969.

[148] O. Bouaziz, N. Guelton, Mater. Sci. Eng. A 319-321 (2001) 246.

[149] A. W. McReynolds, J. Appl. Phys. 20 (1949) 896.

[150] T. Angel, J. Iron Steel Inst. (1954) 165.

[151] V. Seetharaman, R. Krishnan, J. Mater. Sci. 16 (1981) 523.

[152] P. L. Mangonon, G. Thomas, Metall. Trans. 1 (1970) 1577.

[153] S.S. Hecker, M.G. Stout, K.P. Staudhammer, J.L. Smith, Metall. Trans. A 13 (1982) 619.

[154] H.-S. Yang, Design of Low-Carbon, Low-Temperature Bainite, PhD thesis, Pohang

University of Technology, Korea 2011.

[155] F. B. Pickering, Physical Metallurgy and the Design of Steels, 1978.

[156] Q.X. Dai, X.N. Cheng, Y.T. Zhao, X.M. Luo, Z.Z. Yuan, Mater. Charact. 52 (2004) 349.

[157] G. Ghosh, G.B. Olson, J. Phase Equilibria 22 (2001) 199.

[158] C. Capdevila, F.G. Caballero, C. Garcia de Andres, ISIJ Int. 42 (2002) 894.

[159] T. Sourmail, C. Garcia-Mateo, Comput. Mater. Sci. 34 (2005) 323.

[160] H.S. Yang, J.H. Jang, H.K.D.H. Bhadeshia, D.W. Suh, Calphad Comput. Coupling Phase Diagrams Thermochem. 36 (2012) 16.

[161] S. Takaki, H. Nakatsu, Y. Tokunaga, Mater. Trans. JIM 34 (1993) 489.

[162] J.-H. Jun, C.-S. Choi, Mater. Sci. Eng. A 257 (1998) 353.

[163] H. Yang, H. Bhadeshia, Scr. Mater. 60 (2009) 493.

[164] K. Spencer, J.D. Embury, K.T. Conlon, M. Véron, Y. Bréchet, Mater. Sci. Eng. A 387-389 (2004) 873.

[165] G.E. Dieter, in: Mechanical Metallurgy, 3rd Ed., McGraw- Hill, New York, 1986, p. 283. 
[166] B. Petit, N. Gey, M. Cherkaoui, B. Bolle, M. Humbert, Int. J. Plast. 23 (2007) 323.

[167] D. Rousseau, et al., Stabilité structural à la déformation et au froid des aciers inoxydables austénitiques au Cr-Ni, Mé. Scientifiques- Métallurgie 5 (1970) 315.

[168] C. Béranger, B. Baroux, P. Lacombe, Les aciers inoxydables, Les éditions de physique, 1990.

[169] H. Z. Shoji, Kristallogr. 77 (1931) 381.

[170] Z. Nishiyama, Sci. Rep. Tohoku Imp. Univ. 25 (1936) 79.

[171] F. Lecroisey, Transformations martensitiques induites par déformation plastique dans le système Fe-Ni-Cr-C, PhD Thesis, University of Nancy, France, 1971.

[172] G. Vanderschaeve, Phys. Stat. Sol. (A), 100 (1987) 59.

[173] X.Y. San, X.G. Liang, L.P. Cheng, C.J. Li, X. k. Zhu, Mater. Des. 35 (2012) 480.

[174] R. Ueji, Y. Takagi, N. Tsuchida, K. Shinagawa, Y. Tanaka, T. Mizuguchi, Mater. Sci. Eng. A $576(2013) 14$.

[175] G. B. Olson, M. Cohen, Metall. Trans, 7A. 1905, (1976).

[176] P.C. Maxwell, A. Goldberg, J.C. Shyne, Metall. Trans. 5 (1974) 1305.

[177] K.P. Staudhammer, L.E. Murr, S.S. Hecker, Acta Metall. 31 (1983) 267.

[178] A. Das, S. Sivaprasad, M. Ghosh, P.C. Chakraborti, S. Tarafder, Mater. Sci. Eng. A 486 (2008) 283.

[179] Z. Tourki, H. Bargui, H. Sidhom, J. Mater. Process. Technol. 166 (2005) 330.

[180] N. Nakada, H. Ito, Y. Matsuoka, T. Tsuchiyama, S. Takaki, Acta Mater. 58 (2010) 895.

[181] J.R. Patel, M. Cohen, Acta Metall. 1 (1953) 531.

[182] A.J. Bogers, W.G. Burgers, Acta Metall. 12 (1964) 255.

[183] K. Shimizu, M. Oka, C.M. Wayman, Acta Metall. 18 (1970) 1005.

[184] L.E. Murr, K.P. Staudhammer, S.S. Hecker, Metall. Trans. A 13 (1982) 627.

[185] G.B. Olson, M. Cohen, J. Less Common Met. 28 (1972) 107.

[186] L. Bracke, L. Kestens, J. Penning, Scr. Mater. 57 (2007) 385.

[187] X.-S. Yang, S. Sun, X.-L. Wu, E. Ma, T.-Y. Zhang, Sci. Rep. 4 (2014) 6141.

[188] G.B. Olson, M. Cohen, Metall. Trans. 6A (1975) 791.

[189] I.V. Kireeva, Y.I. Chumlyakov, Mater. Sci. Eng. A 481-482 (2008) 737.

[190] H. Wang, X. Sun, P. Yang, W. Mao, L. Meng, J. Mater. Sci. Technol. 31 (2015) 191.

[191] J.F. Breedis, L. Kaufman, Metall. Trans. 2 (1971) 2359.

[192] K. Shimizu, Y. Tanaka, Trans. JIM 19 (1978) 685.

[193] C. Cayron, F. Barcelo, Y. de Carlan, Acta Mater. 58 (2010) 1395.

[194] W. Babyak, F. Rhines, Trans. Metall. Soc. AIME (1960) 218.

[195] D.T. Pierce, J.A. Jiménez, J. Bentley, D. Raabe, J.E. Wittig, Acta Mater. 100 (2015) 178.

[196] Allain S, Bouaziz O, Chateau JP. Proc. int. conf. SHSS. Italia: Verona; 2010.

[197] S. Allain, Comportement mécanique des aciers: des mécanismes fondamentaux à la déformation macroscopique, Mémoire d'Habilitation à Diriger des Recherches, Université de Lorraine, 2012.

[198] D. Barbier, Etude du comportement mécanique et des évolutions microstructurales de l'acier austénitique Fe22Mn0.6C à effet TWIP sous sollicitations complexes. Approche expérimentale et modélisation, PhD thesis, Université Paul Verlaine de Metz, 2009.

[199] S.I. Hong, Mater. Sci. Eng. 79 (1986) 1.

[200] C. Dagbert, M. Sehili, P. Gregoire, J. Galland, L. Hyspecka, Acta Mater. 44 (1996) 2643.

[201] M.G. Stout, P.S. Follansbee, J. Eng. Mater. Technol. 108 (1986) 344.

[202] S. Curtze, V.T. Kuokkala, Acta Mater. 58 (2010) 5129.

[203] C.C. Wu, S.H. Wang, C.Y. Chen, J.R. Yang, P.K. Chiu, J. Fang, Scr. Mater. 56 (2007) 717.

[204] J. A. Lichtenfeld, C.J. Tyne, M.C. Mataya, Metall. Mater. Trans. A 37 (2006) 147.

[205] P.J. Ferreira, J.B. Sande, M.A. Fortes, A. Kyrolainen, Metall. Mater. Trans. A 35 (2004) 3091.

[206] Y. Chen, H.H. Ruan, J. Wang, H.L. Chan, Q. Wang, Q. Li, J. Lu, Acta Mater. 59 (2011) 3697.

[207] D.J. Edwards, E.P. Simonen, S.M. Bruemmer, J. Nucl. Mater. 317 (2003) 13.

[208] C. Pokor, Y. Brechet, P. Dubuisson, J.-P. Massoud, a Barbu, J. Nucl. Mater. 326 (2004) 19. 
[209] O.K. Chopra, Degradation of LWR core internal materials due to neutron irradiation. US Nuclear Regulatory Commission, Office of Nuclear Regulatory Research, 2010.

[210] F.A. Garner, Radiation Damage in Austenitic Steels, 1st ed., Elsevier Inc., 2012.

[211] P.J. Maziasz, J. Nucl. Mater. 205 (1993) 118.

[212] S.J. Zinkle, P.J. Maziasz, R.E. Stoller, J. Nucl. Mater. 206 (1993) 266.

[213] S.M. Bruemmer, E.P. Simonen, P.M. Scott, P.L. Andresen, G.S. Was, J.L. Nelson, J. Nucl. Mater. 274 (1999) 299.

[214] A. F. Rowcliffe, S.J. Zinkle, J.F. Stubbins, D.J. Edwards, D.J. Alexander, J. Nucl. Mater. 258-263 (1998) 183.

[215] L. Tan, R.E. Stoller, K.G. Field, Y. Yang, H. Nam, D. Morgan, B.D. Wirth, M.N. Gussev, J.T. Busby, JOM 68 (2015) 1.

[216] E.A. Kenik, J.T. Busby, Mater. Sci. Eng. R Reports 73 (2012) 67.

[217] K. Fukuya, J. Nucl. Sci. Technol., 50 (2013), pp. 213-254

[218] A. Etienne, B. Radiguet, P. Pareige, J.P. Massoud, C. Pokor, J. Nucl. Mater. 382 (2008) 64.

[219] D.J. Edwards, E.P. Simonen, F.A. Garner, L.R. Greenwood, B.M. Oliver, S.M. Bruemmer, J. Nucl. Mater. 317 (2003) 32.

[220] R.L. Fish, J.J. Holmes, J. Nucl. Mater. 46 (1973) 113.

[221] X. Li, A. Almazouzi, J. Nucl. Mater. 385 (2009) 329.

[222] W. Van Renterghem, A. Al Mazouzi, S. Van Dyck, J. Nucl. Mater. 413 (2011) 95.

[223] Stoller, R. E., Golubov, S. I., \& Barashev, A. V. (2015). Low-Temperature Swelling In Lwr Internal Components: A Computational Assessment. Oak Ridge National Laboratory (ORNL).

[224] J. B. Piochaud, "Modeling of Irradiation induced segregation in Austenitic Fe Alloys at the Atomic Level, PhD Thesis, Université des Sciences et Technologies de Lille, France, 2013.

[225] A. Etienne, B. Radiguet, P. Pareige, J. Nucl. Mater. 406 (2010) 251.

[226] T. Toyama, Y. Nozawa, W. Van Renterghem, Y. Matsukawa, M. Hatakeyama, Y. Nagai, A. Al Mazouzi, S. Van Dyck, J. Nucl. Mater. 418 (2011) 62-68

[227] C. Pokor, Y. Brechet, P. Dubuisson, J.-P. Massoud, X. Averty, J. Nucl. Mater. 326 (2004) 30 .

[228] K.Q. Bagley, J.W. Barnaby, A.S. Fraser, Ukaea, T. Dere, in:, Irradiat. Embrittlement Creep Fuel Cladding Core Components, 1972, p. 143.

[229] P. Kroupa, Philos. Mag. 7 (77) (1962) 783.

[230] M. J. Makin, Philos. Mag. 10 (106) (1964) 695.

[231] G. Saada, J. Washburn, J. Phys. Soc. Jpn. 18 (supplement I) (1963) 43

[232] J. Friedel, Dislocations, Pergamon Press, 1964, p. 454

[233] J. S. Robach, I. M. Robertson, B. D. Wirth, A. Arsenlis, Philos. Mag. 83 (8) (2003) 955.

[234] Y.N. Osetsky, R.E. Stoller, Y. Matsukawa, J. Nucl. Mater. 329-333 (2004) 1228.

[235] Y.N. Osetsky, D. Rodney, D.J. Bacon, Philos. Mag. 86 (2006) 2295.

[236] D. Rodney, Nucl. Instruments Methods Phys. Res. Sect. B Beam Interact. with Mater. Atoms $228(2005) 100$.

[237] J.-B. Baudouin, Modeling and Simulation with Molecular Dynamics of the Edge Dislocation Behavior in the Presence of Frank Loops in Austenitic Stainless Steels Fe-Ni-Cr, PhD Thesis, Institut National des Sciences de Lyon, 2014.

[238] R. L. Fish, J. L. Straalsund, C. W. Hunter and J. J. Holmes, Swelling and Tensile Property Evaluations of High Fluenoe EBR-II Thimbles, Presented at ASTM Annual Meeting (June 1972) Los Angeles, Calif.

[239] N. Hashimoto, S.J. Zinkle, A.F. Rowcliffe, J.P. Robertson, S. Jitsukawa, J. Nucl. Mater. 283$287(2000) 528$.

[240] I.M. Robertson, A. Beaudoin, K. Al-Fadhalah, L. Chun-Ming, J. Robach, B.D. Wirth, A. Arsenlis, D. Ahn, P. Sofronis, Mater. Sci. Eng. A 400-401 (2005) 245.

[241] T. Nogaret, D. Rodney, M. Fivel, C. Robertson, J. Nucl. Mater. 380 (2008) 22.

[242] K. Fukuya, H. Nishioka, K. Fujii, T. Miura, T. Torimaru, J. Nucl. Mater. 417 (2011) 958.

[243] J.I. Cole, S.M. Bruemmer, J. Nucl. Mater. 225 (1995) 53.

[244] G. Sachs, Trans. of the Faraday Soc. 24 (1928) 84. 
[245] G.I. Taylor, J. Inst. Metals 62 (1938) 307.

[246] A. Kochendorfer, M Swanson, Arch Eisenhuttenw 31 (1960) 549.

[247] J.H. Han, K.K. Jee, K.H. Oh, Int. J. Mech. Sci. 45 (2003) 1613.

[248] S. Mader, A. Seeger, C. Leitz, J. Appl. Phys. 34 (1963) 3368.

[249] A. Sato, Y. Sunaga, T. Mori, Acta Metall. 25 (1977) 627.

[250] K.H. Kim, Y.M. Koo, Philos. Mag. A (2001) 479.

[251] J.D. Verhoeven, Fundamentals of physical metallurgy, New York: Wiley, 1974.

[252] H.F. Poulsen, L. Margulies, S. Schmidt, G. Winther, Acta Mater. 51 (2003) 3821.

[253] M.R. Daymond, C.N. Tome, M.A.M. Bourke, Acta Mater. 48 (2000) 553.

[254] G. Winther, L. Margulies, S. Schmidt, H.F. Poulsen, Acta Mater. 52 (2004) 2863.

[255] J.H. Han, K.K. Jee, K.H. Oh, Int. J. Mech. Sci. 45 (2003) 1613.

[256] E. Nagy, V. Mertinger, F. Tranta, J. Sólyom, Mater. Sci. Eng. A 378 (2004) 308.

[257] T. Lorentzsen, T. Leffers, B. Clausen, In: Proc.19th Risø Int. Symp. Mat. Sci. (1998) 345.

[258] D. Barbier, N. Gey, S. Allain, N. Bozzolo, M. Humbert, Mater. Sci. Eng. A 500 (2009) 196.

[259] X. Zhang, T. Sawaguchi, K. Ogawa, F. Yin, X. Zhao, Phil. Mag. Lett. 91 (2011) 563. 